\title{
Vista-LA: Mapping methane-emitting infrastructure in the Los Angeles megacity
}

\author{
Valerie Carranza $^{1, \mathrm{a}}$, Talha Rafiq ${ }^{1,2, \mathrm{a}}$, Isis Frausto-Vicencio ${ }^{1, \mathrm{a}}$, Francesca M. Hopkins ${ }^{1, \mathrm{a}}$, \\ Kristal R. Verhulst ${ }^{1,2}$, Preeti Rao ${ }^{1, b}$, Riley M. Duren ${ }^{1}$, and Charles E. Miller ${ }^{1}$ \\ ${ }^{1}$ Jet Propulsion Laboratory, California Institute of Technology, Pasadena, CA 91109, USA \\ ${ }^{2}$ Joint Institute for Regional Earth System Science and Engineering, University of California, Los Angeles, \\ CA 90024, USA \\ a now at: University of California, Riverside, Riverside, CA 92521, USA \\ ${ }^{b}$ now at: University of Michigan, Ann Arbor, MI 48109, USA
}

Correspondence: Kristal Verhulst (kristal.r.verhulst@jpl.nasa.gov)

Received: 1 July 2017 - Discussion started: 19 July 2017

Revised: 17 January 2018 - Accepted: 20 January 2018 - Published: 28 March 2018

\begin{abstract}
Methane $\left(\mathrm{CH}_{4}\right)$ is a potent greenhouse gas $(\mathrm{GHG})$ and a critical target of climate mitigation efforts. However, actionable emission reduction efforts are complicated by large uncertainties in the methane budget on relevant scales. Here, we present Vista, a Geographic Information System (GIS)-based approach to map potential methane emissions sources in the South Coast Air Basin (SoCAB) that encompasses Los Angeles, an area with a dense, complex mixture of methane sources. The goal of this work is to provide a database that, together with atmospheric observations, improves methane emissions estimates in urban areas with complex infrastructure. We aggregated methane source location information into three sectors (energy, agriculture, and waste) following the frameworks used by the State of California GHG Inventory and the Intergovernmental Panel on Climate Change (IPCC) Guidelines for GHG Reporting. Geospatial modeling was applied to publicly available datasets to precisely geolocate facilities and infrastructure comprising major anthropogenic methane source sectors. The final database, Vista-Los Angeles (Vista-LA), is presented as maps of infrastructure known or expected to emit $\mathrm{CH}_{4}$. Vista-LA contains over 33000 features concentrated on $<1 \%$ of land area in the region. Currently, Vista-LA is used as a planning and analysis tool for atmospheric measurement surveys of methane sources, particularly for airborne remote sensing, and methane "hotspot" detection using regional observations. This study represents a first step towards developing an accurate, spatially resolved methane flux estimate for point sources in SoCAB, with the potential to address discrepancies between bottom-up and top-down methane emissions accounting in this region. The Vista-LA datasets and associated metadata are available from the Oak Ridge National Laboratory Distributed Active Archive Center for Biogeochemical Dynamics (ORNL DAAC; https://doi.org/10.3334/ORNLDAAC/1525).
\end{abstract}

\section{Introduction}

Methane $\left(\mathrm{CH}_{4}\right)$ is the second most important anthropogenic driver of climate change (Myhre et al., 2013). Recent studies have shown that mitigating $\mathrm{CH}_{4}$ emissions yields large near-term climate benefits due to $\mathrm{CH}_{4}$ 's relatively short atmospheric lifetime and high global warming potential (Dlugokencky et al., 2011). Reducing $\mathrm{CH}_{4}$ emissions is complicated by the incomplete understanding of the $\mathrm{CH}_{4}$ budget on policy-relevant spatial scales (e.g., cities to nations). Cities are important for GHG mitigation, since they represent highdensity emissions regions with the appropriate scale to reduce GHG emissions (Duren and Miller, 2012; Kennedy et al., 2009). Additionally, cities have political will and commitment needed to implement mitigation efforts for reducing GHG emissions (Gurney et al., 2015). However, enacting emission controls is challenging in urban areas that are 
highly complex and heterogeneous, with various emissions sources located in close proximity.

Understanding urban emissions requires knowledge of source sectors and their respective activities on scales that reflect their variability across the landscape. Such information has been assembled for fossil fuel carbon dioxide $\left(\mathrm{CO}_{2}\right)$ emissions using the Hestia approach, which quantifies urban sources down to the building level (Gurney et al., 2012). To date, Hestia has been used to generate detailed estimates of urban $\mathrm{CO}_{2}$ emissions for several cities, including Los Angeles (LA) (Rao et al., 2017), Indianapolis (Gurney et al., 2012), and Salt Lake City (Patarasuk et al., 2016). Similar $\mathrm{CH}_{4}$ emissions maps with spatial information equivalent to the scale of Hestia are needed for $\mathrm{CH}_{4}$ emissions mitigation efforts. Studies of spatial patterns of urban $\mathrm{CH}_{4}$ demonstrate considerable fine-scale variability, with $\mathrm{CH}_{4}$ concentrated in hotspots compared to more evenly dispersed $\mathrm{CO}_{2}$ (Hopkins et al., 2016b). This pattern reflects how the sources of $\mathrm{CH}_{4}$ differ significantly from those of $\mathrm{CO}_{2}$, which are primarily driven by fossil fuel combustion. Therefore, the methods used to develop Hestia are not directly transferable to $\mathrm{CH}_{4}$, which has source processes and spatial patterns distinct from $\mathrm{CO}_{2}$.

Urban areas are globally significant sources of $\mathrm{CH}_{4}$ emissions; however, correct quantification and source attribution on the scale of individual cities are highly uncertain. Global emissions inventories based on nightlights and/or population scaling methods (e.g., EDGAR v4.2 European Commission Joint Research Centre, 2010; Olivier and Peters, 2005) are limited in their usefulness for estimating emissions at the scale of a city or air basin, as demonstrated for So$\mathrm{CAB}$ by Wunch et al. (2009). Official $\mathrm{CH}_{4}$ emissions inventories made using bottom-up approaches are often created for policy and planning purposes at the state and national level (IPCC, 2006; CARB, 2016; EPA, 2016); however, $\mathrm{CH}_{4}$ sources in cities often differ substantially from these totals because they lack information on the spatial distribution of emissions sources in urban regions, such as the high density of fossil fuel usage and relative lack of agricultural activities. Furthermore, these inventories are not directly comparable to urban-scale atmospheric observations increasingly used by researchers to assess city-wide greenhouse gas emissions. When scaled down to the city level, these bottom-up emissions inventories have been shown to underestimate $\mathrm{CH}_{4}$ emissions and apportion those $\mathrm{CH}_{4}$ emissions to a different mixture of sources. Such discrepancies have been observed in many North American and European cities, including the greater Los Angeles (LA) region (Hopkins et al., 2016b; Hsu et al., 2009; Townsend-Small et al., 2012; Wennberg et al., 2012; Wong et al., 2015, 2016; Wunch et al., 2009), Boston (McKain et al., 2015), Indianapolis (Cambaliza et al., 2015), Florence (Gioli et al., 2012), London (Helfter et al., 2016), and San Francisco (Jeong et al., 2017). Consequently, there is a need for a new approach for assessing urban $\mathrm{CH}_{4}$ emis- sions that is able to incorporate both top-down (observationbased) and bottom-up (activity-based) information.

Recent efforts have been made to spatially disaggregate $\mathrm{CH}_{4}$ emissions by sector for California and United States inventories, resulting in $0.1^{\circ} \times 0.1^{\circ}$ gridded $\mathrm{CH}_{4}$ emissions products that coarsely represent the city scale (CALGEM: Jeong et al., 2013; Maasakkers et al., 2016); however, these $\sim 10 \mathrm{~km}$ scales are still too coarse for interpreting new finescale observations. Inaccuracies and coarse spatial information in city-scale $\mathrm{CH}_{4}$ emissions inventories pose a direct obstacle to city mitigation plans. One hypothesis for the discrepancy between $\mathrm{CH}_{4}$ observations and inventories in cities is that fugitive emissions, particularly from natural gas systems, are currently underrepresented in inventories. A related hypothesis suggests that this discrepancy stems from undercounting disproportionately large $\mathrm{CH}_{4}$ "super-emitters" such as those that have been shown to occur in natural gas systems (Brandt et al., 2014). New observations to identify the location of fugitive emissions and $\mathrm{CH}_{4}$ super-emitters are currently being made in urban areas using mobile surveys, airborne campaigns, and sustained monitoring (e.g., Cambaliza et al., 2015; Hopkins et al., 2016b; Verhulst et al., 2017). To test these hypotheses, parallel efforts to map $\mathrm{CH}_{4}$ emissions sources and accurately represent $\mathrm{CH}_{4}$ emissions are needed at the urban scale, as has been done for oil and gas extraction in the Barnett Shale (Lyon et al., 2015; Zavala-Araiza et al., 2015). $\mathrm{CH}_{4}$ emissions estimates for urban regions can be improved by more complete accounting of potential $\mathrm{CH}_{4}$ sources at the facility scale, along with targeted observations that can detect fugitive emissions and super-emitter behavior.

Here, we present Vista-LA, a Geographic Information System (GIS)-based approach to map potential methane emissions sources in the South Coast Air Basin (SoCAB), which includes all of Orange County and the non-desert regions of Los Angeles, Riverside, and San Bernardino counties. Our primary goal is to improve understanding of $\mathrm{CH}_{4}$ emissions on urban scales with complex mixtures of sources, exemplified by the LA megacity within SoCAB. Emissions monitoring and verification efforts in LA are highly relevant for California's statewide emissions control efforts. The LA megacity emits a significant fraction of California's GHG emissions (Jeong et al., 2016). Vista-LA consists of detailed spatial maps for facilities and infrastructure in So$\mathrm{CAB}$ that are known or expected sources of $\mathrm{CH}_{4}$ emissions, representing a first step towards developing an urbanscale $\mathrm{CH}_{4}$ emissions gridded inventory for SoCAB. The current release of the Vista-LA database contains over 33000 entries, which are presented as $\mathrm{CH}_{4}$-emitting infrastructure maps. SoCAB is an ideal testbed due to the density of sources and availability of observations from the LA Megacity Carbon Project (https://megacities.jpl.nasa.gov/portal/) tower network (Newman et al., 2016; Verhulst et al., 2017), the California Laboratory for Atmospheric Remote Sensing (CLARS; Wong et al., 2016, 2015), and a Total Column Carbon Observing Network site (TCCON; Wunch et al., 2009). 


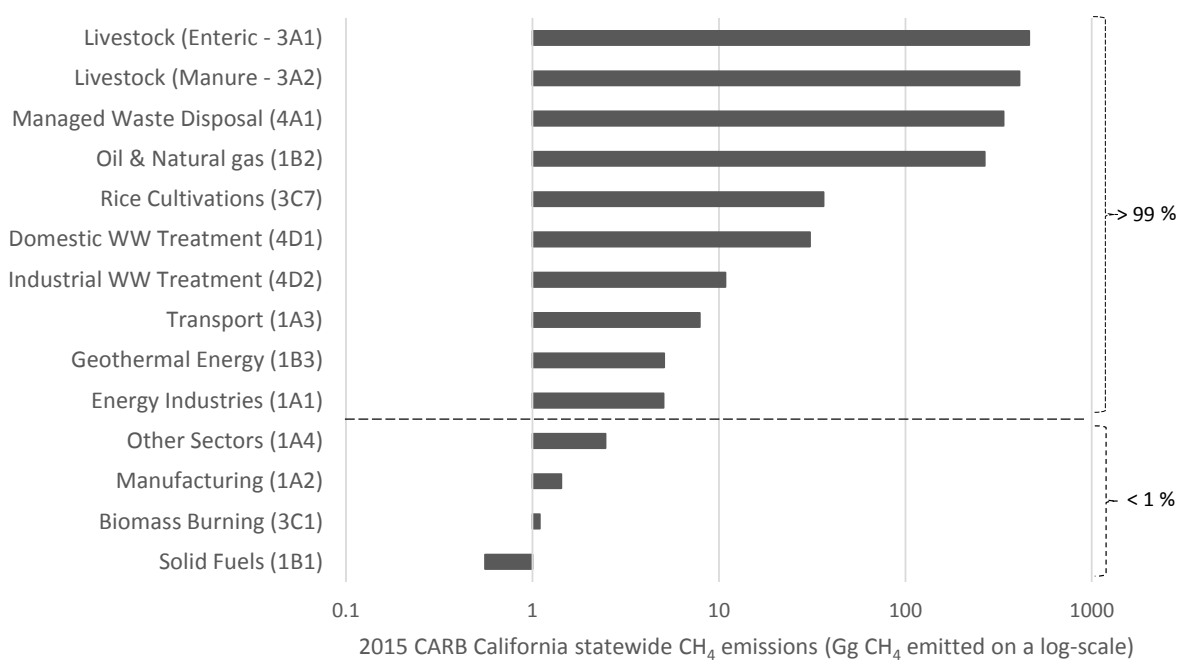

Figure 1. Ranking of inventoried California $\mathrm{CH}_{4}$ emissions for 2015 by IPCC Level 3 categories. This figure shows the total emitted Gg of $\mathrm{CH}_{4}$ for each IPCC sector on a logarithmic scale as calculated by CARB for the year 2015. These data are based on IPCC Level 3 categories which are indicated in parentheses next to each source type. Only the top 14 of 35 IPCC Level 3 categories are shown for clarity. The total 2015 emission from these 14 sectors was $1576 \mathrm{Gg}$ of $\mathrm{CH}_{4}$. The top 10 IPCC Level 3 categories encompass roughly $>99 \%$ of California's statewide $\mathrm{CH}_{4}$ emissions ( $\left.\sim 1570 \mathrm{Gg} \mathrm{CH}_{4}\right)$. We excluded emissions from the Vista-LA database that come from non-stationary sources (i.e., transport, IPCC - 1A3) and that are non-existent in the SoCAB region (i.e., imported electricity, IPCC - 1A1, coal mining, IPCC - 1A2, geothermal energy, IPCC - 1B3, and rice cultivation, IPCC - 3C7). Note that while livestock and waste are the most significant sources of $\mathrm{CH}_{4}$ in the State of California, atmospheric $\mathrm{CH}_{4}$ in the Los Angeles urban landscape is dominated by $\mathrm{CH}_{4}$ hotspots from fossil fuel-derived sources (e.g., Hopkins et al., 2016b). WW refers to wastewater treatment plants.

The Vista-LA data product is a key tool for $\mathrm{CH}_{4}$ emissions research and mitigation efforts by (1) mapping areas of $\mathrm{CH}_{4}$ emitting infrastructure, (2) identifying targets for $\mathrm{CH}_{4}$ surveys, and (3) enabling interpretation of atmospheric observations, including source attribution, and comparison of measured emissions to permitted or reported emissions. Combined with atmospheric observations, Vista-LA enables systematic study of urban $\mathrm{CH}_{4}$ emissions sources.

\section{Methods overview}

\subsection{Vista-LA structure and organization}

The spatial domain for the Vista-LA database is SoCAB, the air-shed for the greater Los Angeles urban extent, including all of Orange County and the urbanized parts of Los Angeles, Riverside, and San Bernardino counties. Vista-LA follows the framework of the 2006 Intergovernmental Panel on Climate Change Guidelines for National GHG Inventories for $\mathrm{CH}_{4}$ emissions (IPCC, 2006). Following the IPCC methodology provides compatibility with the State of California GHG Inventory for $\mathrm{CH}_{4}(\mathrm{CARB}, 2014,2015)$ and allows the approach used in this study to be translated to other regions globally. For example, Vista-LA can be easily adapted to the Environmental Protection Agency (EPA)'s Inventory of the United States GHG Emissions and Sinks since it also follows the 2006 IPCC Guidelines for National GHG Inventories (see Appendix Fig. A1; EPA, 2016).
The Vista-LA structure enables sectoral tracking of emissions. We used the State of California GHG Inventory for 2015 (CARB, 2016), the most policy-relevant inventory that includes the SoCAB domain, to rank the top $\mathrm{CH}_{4}$-emitting sources (Fig. 1). According to the State of California GHG Inventory, $\sim 99 \%$ of California's $\mathrm{CH}_{4}$ emissions are expected to result from just three IPCC Level 1 categories - energy, agriculture, and waste - and 10 IPCC Level 3 categories (see Fig. 1). The other IPCC Level 3 categories cumulatively contribute $<1 \%$ of California's $\mathrm{CH}_{4}$ emissions, and are hence assumed to have a negligible impact on $\mathrm{SoCAB} \mathrm{CH}_{4}$ emissions. This approach greatly simplifies the database, allowing us to focus our attention on the top-emitting sources. By design, Vista-LA only includes stationary sources and Scope 1 emissions - that is, direct GHG emissions from sources that are owned or controlled by a company within the study domain, as defined by the GHG Protocol (http://www. ghgprotocol.org/corporate-standard). Therefore, sources that are not expected to result in significant direct emissions of $\mathrm{CH}_{4}$ in SoCAB were excluded, such as emissions from imported electricity, geothermal energy production, rice cultivation and solid fuels such as coal.

Vista-LA also includes two additional sources that are not explicitly accounted for in the State of California GHG Inventory but are potentially significant sources of fugitive $\mathrm{CH}_{4}$ emissions in SoCAB: compressed natural gas (CNG) fueling stations and liquefied natural gas (LNG) fueling sta- 
tions, which were categorized under IPCC - 1B2. This case study of Vista-LA focuses on anthropogenic sources of $\mathrm{CH}_{4}$, and every effort has been made to make the Vista-LA dataset as complete, accurate, and timely as possible. Because VistaLA is designed to incorporate solely anthropogenic sources of $\mathrm{CH}_{4}$, natural $\mathrm{CH}_{4}$ sources such as wetlands and geologic seeps are excluded this version. This is consistent with the most recent version of the California GHG Inventory, which categorizes petroleum gas seeps separately as "excluded" emissions, though they were previously categorized under IPCC - 1B2.

\subsection{Overview of data sources}

Within each of the three major $\mathrm{CH}_{4}$ source sectors (IPCC 1 Energy; IPCC 3 - Agriculture, Forestry, and other Land Use; and IPCC 4 - Waste), we identified the types of infrastructure associated with known or potential emissions. We sought out publicly available datasets that mapped their spatial locations (Table 1). Spatial datasets were compiled from reliable and verified public databases on government and federal/state research agency portals. The data are presented as shapefiles and $\mathrm{kmz}$ files that include points, lines, and polygons. Table 1 summarizes the spatial datasets by the year, source of data, or data type (points, lines, or polygon data), and also indicates the corresponding IPCC Level $3 \mathrm{CH}_{4}$ emissions category. While point sources are our primary interest, we have provided polygons in Vista-LA to expedite attribution since the area associated with a given facility, landfill, dairy, etc. is the ownership unit. Additionally, there may be many different source classes within a given polygon - for example wellheads, storage tanks, compressors, or pipelines - and having the polygon/operator identity in our classification hierarchy provides critical information on traits such as behavior, processes, and facility history. Lines are the natural representation for pipelines and transmission infrastructure. Sections 3-5 describe the data sources and information in Vista-LA in further detail and also describe the specific data processing techniques applied to the GIS dataset for each of the Level 3 emissions categories.

Some of the spatial datasets we obtained (see, e.g., the Southern California Association of Governments, http: //gisdata.scag.ca.gov/Pages/GIS-Library.aspx) and the EPA Facility Registry Service (FRS) were useful for evaluating information from more than one type of $\mathrm{CH}_{4}$-producing infrastructure (e.g., petroleum refineries and wastewater treatment plants). Due to the variety of data sources used to create Vista-LA, the same level of detail (e.g., spatial resolution, data completeness, available metadata) was not always available for every $\mathrm{CH}_{4}$-emitting source. The level of completeness or detail for each spatial dataset will be discussed below under the data sources and limitations sections. We processed and standardized GIS datasets through georeferencing, spatial configuration, and verification using ArcGIS software packages. All spatial features and raster layers were geolocated using the World Geodetic System 1984 datum and the Universal Transverse Mercator Zone 11 North coordinate system. Considerations for privacy including restrictions and limitations on some of these datasets were taken into account for the final product. Consequently, Vista-LA datasets for natural gas compressor stations and natural gas pipelines are only included as static representations in Figs. 2 and 3. Vista-LA does not include sub-facility-level information. Timely data are critical for understanding methane dynamics in SoCAB; therefore, we used the most recent publicly available information in the development of the VistaLA database.

\section{Energy (IPCC Level 1 - Category 1)}

The Energy (IPCC Level $1-1$ ) sector includes $\mathrm{CH}_{4}$ emitted by fuel combustion activities (IPCC Level $2-1 \mathrm{~A}$ ) and fugitive emissions from fuels (IPCC Level $2-1 \mathrm{~B}$ ). $\mathrm{CH}_{4}$ emissions from fuel combustion are mainly produced by energy industries and transportation, with minor contributions from manufacturing, commercial, industrial, residential and agricultural fuel combustion (CARB, 2016). Fugitive emissions are defined by the IPCC as an intentional or unintentional release of gas from anthropogenic activities not including combustion (IPCC, 2001). Fugitive $\mathrm{CH}_{4}$ emissions come from leaks or failures of equipment, off-gassing, or venting, arising from sources such as natural gas storage facilities, oil and gas wells, and pipelines. They occur mainly in the oil and gas sector ( $\sim 95 \%$ of California's estimated fugitive $\mathrm{CH}_{4}$ according to CARB, 2016), with a small contribution from industrial and manufacturing sources. Many facilities, including petroleum refineries and power plants, include both combustion and fugitive $\mathrm{CH}_{4}$ emissions.

\subsection{Fuel Combustion Activities (IPCC Level 2 - 1A)}

Fuel combustion activities (IPCC Category 1A) include $\mathrm{CH}_{4}$ emissions from energy industries, which encompass petroleum refining and electricity generation via combustion of natural gas in power plants, and transportation. Other combustion sources have only a small expected $\mathrm{CH}_{4}$ emission rate (totaling $<0.1 \%$ of statewide $\mathrm{CH}_{4}$ ), according to the California GHG Inventory, hence are not included in Vista-LA (CARB, 2016). The physical infrastructure associated with combustion and fugitive $\mathrm{CH}_{4}$ emissions from energy industries in SoCAB are natural gas-fired power plants and petroleum refineries. Transportation comprises $\sim 1 \%$ of inventoried statewide $\mathrm{CH}_{4}$, primarily from on-road sources (e.g., conventionally fueled cars, light- and heavyduty trucks), but is not included in this version of Vista-LA (CARB, 2016). 


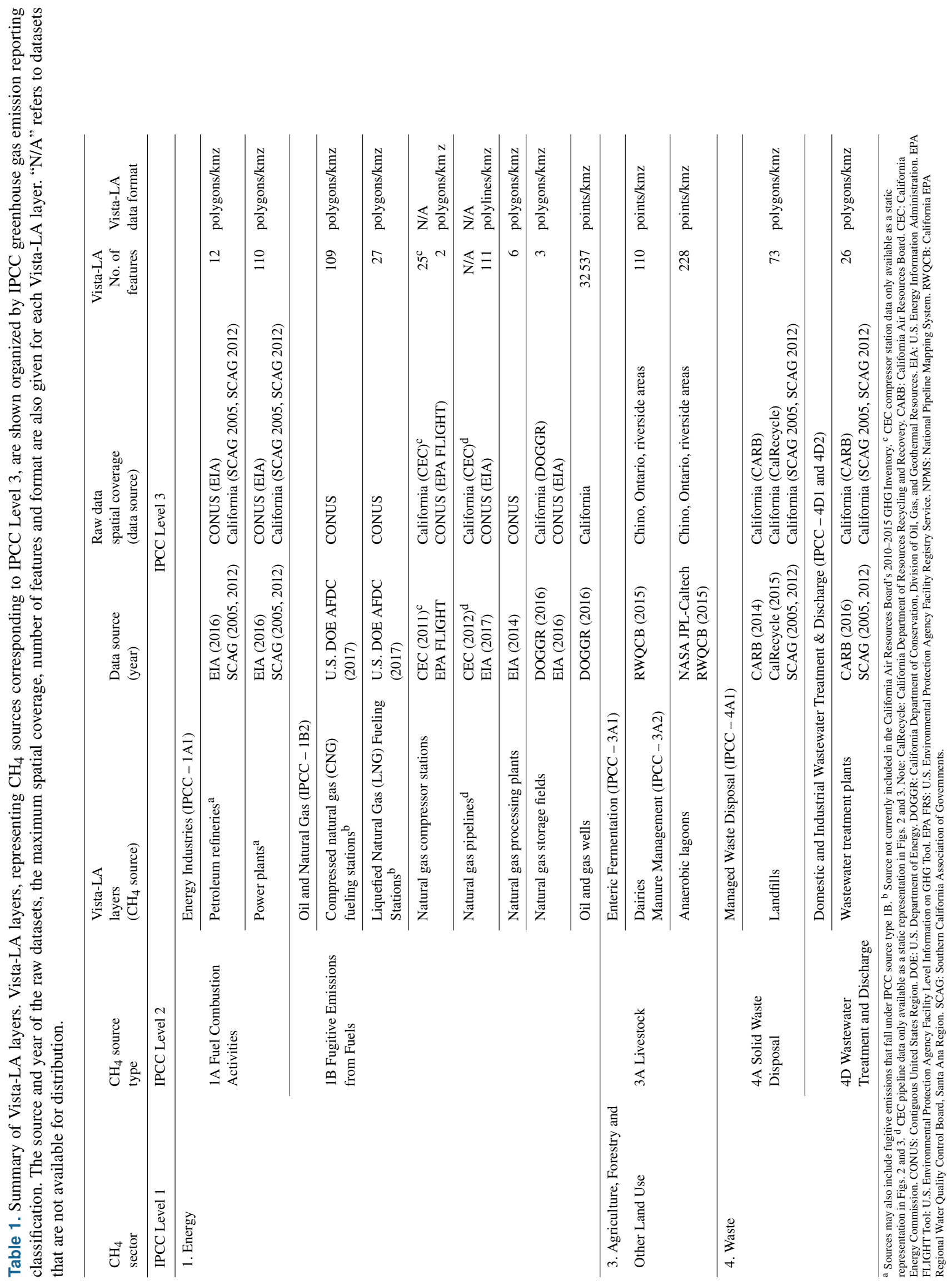



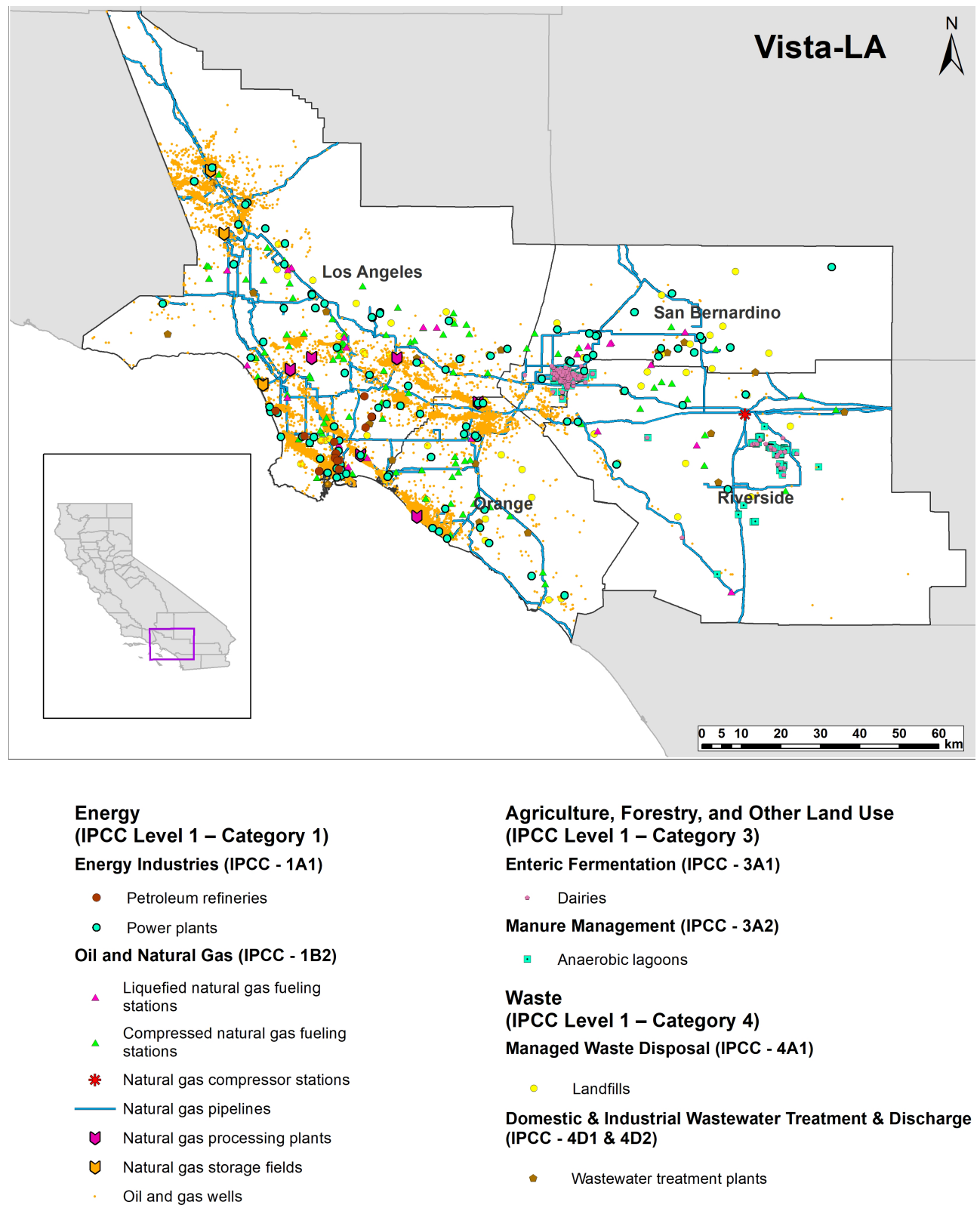

Figure 2. Overview of Vista-LA. Locations are shown for infrastructure with known or expected potential to emit $\mathrm{CH}_{4}$ in $\mathrm{SoCAB}_{\text {. Vista }}$ layers are categorized by their corresponding IPCC Level 3 from the State of California GHG Inventory (see Table 1). Currently, compressed and liquefied natural gas fueling stations and natural gas storage fields are not included in the California GHG emissions inventory, but may be a significant source of fugitive $\mathrm{CH}_{4}$ emissions in SoCAB (see, e.g., Conley et al., 2016; Hopkins et al., 2016b). Note: infrastructure in polygon form is difficult to distinguish from a static zoomed-out image; however, the majority of Vista-LA layers can be viewed at the meter scale. Exceptions to this rule are for natural gas compressor stations and natural gas pipelines due to privacy and security concerns. Total: 33354 features across 13 layers: 9 polygon layers; 3 point layers; 1 polyline layer.

\subsubsection{Energy Industries (IPCC Level 3-1A1)}

\section{Petroleum refineries (Vista-LA layer)}

Data sources. The Vista-LA petroleum refinery dataset provides location and extent data for 12 facilities in the domain. The primary spatial datasets for petroleum refineries (IPCC - 1A1) were gathered from the U.S. Energy Infor- mation Administration (EIA) for the year 2016. EIA reports information about all operable petroleum refineries and electricity generation plants in the United States, including plants that are active, on standby, and those short-term or long-term out of service (EIA, 2016). Additional information came from Southern California Association of Governments (SCAG) land-use data for the years 2005 and 2012 (see 


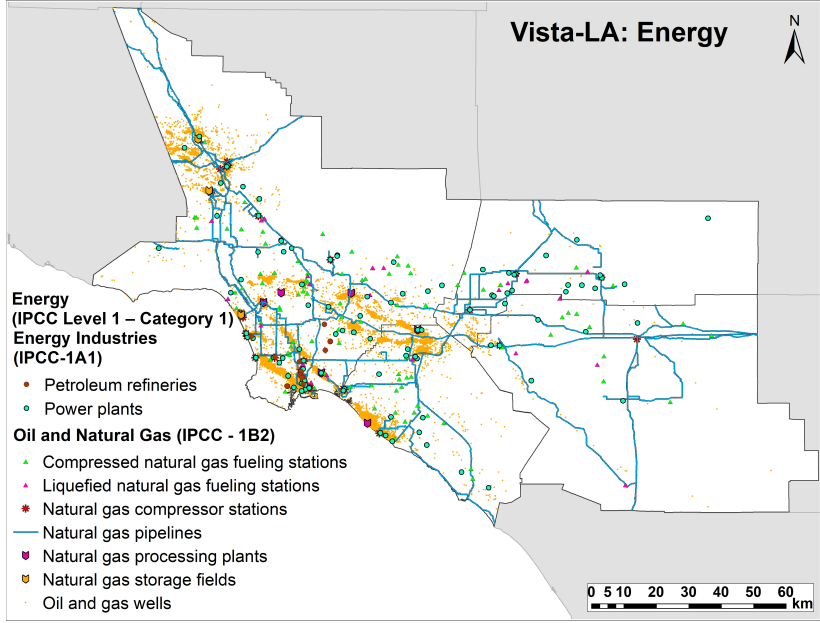

Figure 3. Energy (IPCC Level 1 - Category 1). Spatial distribution of infrastructure associated with the energy industry that emit $\mathrm{CH}_{4}$ through fuel combustion (IPCC - 1A1) and/or fugitive emissions (IPCC - 1B2). Natural gas storage fields and compressed and liquefied natural gas fueling stations are currently not explicitly inventoried in the California GHG emissions inventory. Note: infrastructure in polygon form is difficult to distinguish from a static zoomed-out image; however, the majority of Vista-LA layers can be viewed at the sub-meter level. Exceptions to this rule are for natural gas compressor stations and natural gas pipelines due to privacy and security concerns.

http://gisdata.scag.ca.gov/Pages/GIS-Library.aspx).

Data processing, validation and limitations. Petroleum refinery locations were verified using multiple datasets, including EIA, SCAG, Esri Basemap aerial imagery, and Google Earth imagery. EIA was the primary source of information, as it contains the most recent data. SCAG and the U.S. Environmental Protection Agency's Facility Level Information on GHG online reporting Tool (EPA FLIGHT) were used to verify that there were no missing petroleum refineries from EIA. This process provided data quality assurance from the most updated publicly available spatial database of petroleum refineries.

The original EIA data series on petroleum refineries includes geolocations as points, and information on production capacity, current and projected capacity of crude oil separated by atmospheric distillation, downstream charge, as well as fuel, electricity, and steam purchased and consumed by 141 refineries across the United States (U.S. Energy Information Administration, 2015). This dataset contains information on nine refineries located in SoCAB, all of which are located in Los Angeles County.

To map the area of petroleum refinery and power plant facilities, we added data from SCAG for the years 2005 and 2012, which map land-use areas to a minimum two-acre resolution (see http://gisdata.scag.ca.gov/Pages/GIS-Library. aspx). The SCAG database only contains land-use classifica- tions for the State of California, and lacks facility-level information. We performed feature identification using SCAG land-use code 1322 "Petroleum Refining and Processing". This category includes major oil refineries, as well as associated petrochemical plants. The data were used to identify, extract, and define the spatial extent of each refinery and to match the geolocations of the refineries listed in the EIA 2016 dataset.

The SCAG land-use code was used to identify and extract 30 polygons in the SCAG 2005 dataset and 60 polygons in the SCAG 2012 dataset related to petroleum refineries in So$\mathrm{CAB}$. Because SCAG polygon features were fragmented and not assigned to an individual refinery, they had to be manually merged based on their geolocation and spatial relation to the EIA 2016 dataset. The polygon features dataset categorized as "Petroleum Refining and Processing" was merged together and then compared to the nine refineries identified in the raw EIA dataset. In some cases, these SCAG polygon features were geographically misplaced in residential locations or in the middle of streets and had to be manually adjusted to fit the actual extent of that facility. There were three facilities identified in the SCAG dataset that were not identified in the EIA dataset. The existence and operation of these three facilities identified in SCAG were further verified using refinery planning documents and environmental assessment reports and then were appended to the EIA dataset. The true spatial extent of all polygons was verified using aerial imagery. During validation of refinery spatial extents with Google Earth Imagery and Esri Basemap aerial imagery, focus was placed on identifying acres of storage tanks situated in a matrix formation, large intake pipes, storage vats, and large industrial infrastructure.

The additional refineries identified in SCAG and validated through the Vista verification procedures do not contain facility-level metrics that were provided in the EIA dataset. Obtaining detailed sub-facility-level information for each petroleum refinery will be crucial to developing accurate $\mathrm{CH}_{4}$ emission factor estimates, which is a limitation of the current dataset.

Results. The final Vista-LA petroleum refinery dataset includes all 12 petroleum refineries operated by eight different companies within SoCAB (Figs. 2 and 3). The final dataset includes operational data from EIA, recalculated locational data, and validation notes including any changes made and date of last update. 


\section{Power plants (Vista-LA layer)}

Data sources. The Vista-LA layer for power plants (IPCC - 1A1) relies on data from EIA, SCAG 2005, SCAG 2012, Google Earth and Esri Basemap aerial imagery (EIA, 2016; see http://gisdata.scag.ca.gov/Pages/GIS-Library.aspx). The Vista-LA power plant dataset provides accurate location and extent data as well as facility-level information on the type of power generation methods and energy production statistics.

Data processing, validation and limitations. The EIA 2016 contains records for 7995 power plants in the United States, including 385 power plants in SoCAB. For our analysis, we selected only the power plants that used the following primary fuels: biomass, natural gas, petroleum, or other which matches the methods of the California GHG Inventory (CARB, 2016). This excluded power plants with primary fuel categories such as wind, solar, hydroelectric, or pumped storage. After filtering by primary fuel type, we retained a subset of 110 power plants in SoCAB.

Polygon features for each of the 110 power plants were created based on Google Earth Imagery, Esri Basemap Aerial Imagery, and SCAG 2005 and SCAG 2012 land-use datasets. SCAG land-use code 1431 ("Electrical Power Facilities") was used to verify and determine the spatial extent of the EIA power plants. SCAG polygons were geolocated with the point data from the EIA dataset. In total, there were 1490 individual polygon features related to land-use code 1431 in SCAG 2005 and 6932 in SCAG 2012. In addition to power plants, SCAG land-use code 1431 also includes land used for distribution of electricity and substations with power plants; hence, visual inspection using high-resolution aerial imagery was required to validate each individual power plant and to generate accurate polygon representations.

When visually inspecting individual power plants, we looked for typical power plant infrastructure features such as smoke or steam stacks with towers, racks, piping, vents, transformers and/or electrical equipment. Some power plant locations were more difficult to validate. In some cases, the power plant point data were placed on the street near the operating utility and sometimes did not match the address that was listed in the metadata. Sometimes the point was located in the center of a site, which could be within another facility (e.g., a refinery) and thus had to be manually adjusted with appropriate understanding of the context of its location using Google Earth and Esri Basemap aerial imagery. Polygons were created using GIS methods including geoprocessing and digitizing with Google Earth and Esri Basemap aerial imagery as a reference. Latitude and longitude coordinates were recalculated appropriately for each power plant. Power plants whose geolocations were verified but whose spatial extent could not be determined using this method were tagged with a circular placeholder and their
EIA facility-level metrics were maintained and marked in the metadata.

We used the 2014 Fossil Fuel Data Assimilation System (FFDAS) point dataset to validate our results (AsefiNajafabady et al., 2014). The 105 power plant point locations in the 2014 FFDAS dataset match with $105 / 110$ power plants in the final Vista-LA layer. The FFDAS dataset includes only those facilities registered through the EPA's Clean Air Markets Division and EIA reporting, which explains the difference in the number of locations between the two datasets. One of the five plants is a landfill gas plant, so it is not tracked in FFDAS because it is not a fossil-based source of $\mathrm{CO}_{2}$ emissions.

We also considered using the 2010 Open-source Data Inventory for Anthropogenic $\mathrm{CO}_{2}$ (ODIAC) for validation of power plants (Oda and Maksyutov, 2011). Cross-validation with ODIAC was not straightforward because the online data product is gridded and is at a lower resolution than the EIA and SCAG datasets. The publicly available version of ODIAC also had significant latency compared to the EIA and SCAG datasets used in this study.

Results. The Vista-LA power plant dataset merged polygon extent data with the EIA metadata. The final dataset includes the facility-level statistics from EIA along with data validation information using Google Earth, SCAG 2005, and SCAG 2012 in the metadata for all 110 power plants originally identified in the EIA dataset (Figs. 2 and 3). We include the production metrics in the Vista-LA database, as they may be useful for generating $\mathrm{CH}_{4}$ emissions estimates in the future.

\subsection{Fugitive Emissions from Fuels (IPCC Level 2 - 1B)}

Fugitive emissions from fuels (IPCC Category 1B) include $\mathrm{CH}_{4}$ emissions from the lifecycle (production, processing, storage, transportation) of oil, natural gas, solid fuels, and geothermal energy production occurring in SoCAB. We omit the latter two sources from consideration since California air-quality restrictions do not permit coal-burning (Perata, 2006), and there are no active coal mining or geothermal energy sites in SoCAB. In the California GHG Inventory, fugitive emissions are primarily from oil and gas extraction $(30 \%)$ and natural gas pipelines $(65 \%)$ (CARB, 2016). Vista-LA includes spatial information for oil and gas wells, natural gas pipelines, natural gas storage fields, natural gas processing plants, and natural gas compressor stations. Petroleum refineries emit fugitive $\mathrm{CH}_{4}$ (IPCC 1B2), in addition to combustion emissions (IPCC 1A1). For simplicity, the Vista-LA database does not treat these emissions separately because both emission types are encompassed at the facility level (see Sect. "Petroleum refineries" for more information on the Vista-LA layer on petroleum refineries). We also include two more potentially significant sources of fugitive $\mathrm{CH}_{4}$ emissions in SoCAB that have no assignment 
in the California GHG Inventory or IPCC categories: compressed natural gas $(\mathrm{CNG})$ fueling stations and liquefied natural gas (LNG) fueling stations. Vista-LA does not yet include the locations of petroleum storage tanks due to a lack of publicly available information for these elements. Data for energy-related sources are also available for purchase from consulting companies; however, one of the objectives of this work was to generate a product that is openly accessible to the public. Therefore, we did not utilize proprietary or "forpurchase" information in the development of the Vista-LA database.

\subsubsection{Oil and Natural Gas (IPCC Level 3 - 1B2)}

\section{Compressed natural gas (CNG) fueling stations (Vista-LA} layer)

Data sources. Geospatial data of active CNG fueling stations were obtained from the U.S. Department of Energy's (DOE) Alternative Fuels Data Center (AFDC) for the year 2017 (DOE, 2017). Currently, CNG fueling stations are not included in a separate IPCC category. For the purposes of this study we have classified these data under IPCC Level 3 $1 \mathrm{~B} 2$.

Data processing, validation and limitations. The raw file was downloaded from DOE/AFDC through a series of queries for CNG fueling stations. Next, the CNG dataset was geocoded using latitude-longitude coordinates. Coordinates for this dataset generated points for 1792 stations across the United States, including 336 in the State of California; 163 of the 336 compressed natural gas stations were in SoCAB, further reduced to 109 after removing duplicate entries. The geolocations of these $109 \mathrm{CNG}$ fueling stations were verified by comparing the reported street address to Google aerial imagery (e.g., Google Earth, Google Maps, and Google Earth Street View) and Esri Basemaps. Out of the 109 points, 88 polygon extent features were created based on aerial imagery. For the remaining $21 \mathrm{CNG}$ stations, placeholder polygons were created for stations whose natural gas infrastructure could not be visually identified using aerial imagery but whose location was otherwise verified. During visual validation of the CNG stations, we focused on identifying pumps, gas station infrastructure, and piping/compressed gas storage cylinders near parking lots and salvage yards.

A major portion of the DOE/AFDC dataset placed the locations of $\mathrm{CNG}$ fueling stations adjacent to the fueling station, making it challenging to discern the exact location of station infrastructure on the map. This dataset counts the entire station as one polygon, despite multiple fuel dispensers. Sub-facility-level information about individual fueling dispensers is not currently identified in Vista-LA.

Results. The final Vista-LA CNG fueling station layer contains geolocations for 109 polygons. Figures 2 and 3 show the spatial distribution of the Vista CNG fueling station layer. The metadata contain information about the station name, pressures (units: pounds per square inch or psi), types of dispensing capability, maximum vehicle size accommodation, and recalculated latitude and longitude coordinates, along with validation notes including any changes made and date of last update.

\section{Liquefied natural gas (LNG) fueling stations (Vista-LA layer)}

Data sources. Similar to CNG stations, fugitive emissions from LNG fueling stations were not inventoried in the 2015 California GHG Inventory. Thus, we assigned LNG stations under IPCC - 1B2. Geospatial data of active LNG fueling stations were obtained from the U.S. Department of Energy's (DOE) Alternative Fuels Data Center (AFDC) for the year 2017 (DOE, 2017).

Data processing, validation and limitations. The DOE data were originally geocoded using the coordinates listed. The raw DOE dataset contained 187 records of LNG stations across the U.S.; 47 of those stations were located in the State of California, with 27 currently open and operational in So$\mathrm{CAB} ; 15$ of the $27 \mathrm{LNG}$ stations shared the same location as CNG stations. The geolocations of the 12 LNG-only stations were verified by comparing the reported street address to Google aerial imagery and Esri Basemap aerial imagery. Similar to the CNG stations, extent polygons were generated of the remaining 12 stations using aerial imagery. During visual validation of the LNG stations, focus was placed on identifying gas station infrastructure and piping/compressed gas storage cylinders near parking lots and salvage yards.

This dataset is updated annually by the DOE, meaning additional validation will need to be completed in the future as more LNG fueling stations come online. Two stations were already listed as being planned in SoCAB and will be operational in less than a year and will need to be added to the dataset in the future. Similar to the CNG dataset, the LNG dataset assigns the entire station as one polygon, regardless of the number of fuel dispensers.

Results. The final Vista-LA LNG fueling station dataset contains polygons for 27 stations in SoCAB. Figures 2 and 3 show the spatial distribution of the Vista-LA LNG fueling station layer. The LNG dataset also includes metadata describing the station name, pressures (units: psi), types of dispensing capability, maximum vehicle size accommodation, recalculated GPS coordinates, and validation notes including any changes made and date of last update.

\section{Natural gas compressor stations (Vista-LA layer)}

The natural gas compressor station (IPCC - 1B2) dataset was obtained using the U.S. Environmental Protection Agency's 
Facility Level Information on GHG online reporting Tool (EPA FLIGHT) and from the and California Energy Commission (CEC). From EPA FLIGHT, we identified two natural gas compressor stations in SoCAB. CEC lists 25 compressor stations in SoCAB. The locations of natural gas compressor stations were validated using Google Earth and Esri Basemap aerial imagery (EPA, 2015). Due to restrictions, we only show the location of the compressor station facility reported in EPA FLIGHT in Figs. 2 and 3.

\section{Natural gas pipelines (Vista-LA layer)}

Information for natural gas pipelines (IPCC - 1B2) was collected from the CEC and the EIA 2017 dataset (Maasakkers et al., 2016). The CEC dataset provides infrastructure information on major gas transmission and hazardous liquid transmission pipelines in the United States for the year 2012 (CEC, 2012). For California, the raw CEC dataset was georeferenced and clipped to fit the spatial extent of SoCAB. We also obtained high-resolution natural gas transmission pipeline maps from the National Pipeline Mapping System (NPMS) (NPMS, 2013) to validate the CEC pipeline layers. The NPMS dataset includes a level of detail similar to that of the CEC dataset, but can be obtained for the entire U.S. There were very minor differences between the CEC and NPMS layers; however, because the NPMS restricts distribution or visualization of these data, they were retained for internal use only. Due to security concerns, the CEC dataset is only shown as static representations in Figs. 2 and 3.

Unlike the CEC and NPMS data, the EIA dataset is available publicly. The EIA dataset has a lower level of accuracy compared to the CEC dataset. The positional accuracy of the EIA dataset is $\pm 3000 \mathrm{~m}$, while the positional accuracy of CEC is $\pm 150 \mathrm{~m}$. The EIA dataset also contains less information on the disaggregation of pipeline segments. The final Vista-LA natural gas pipeline dataset includes a georeferenced and processed version of the EIA dataset and contains 111 polyline segments; however, due to the uncertainties noted, it would be ideal to use more spatially resolved datasets for future work.

\section{Natural gas storage fields (Vista-LA layer)}

Data sources. Under IPCC - 1B2, natural gas storage facility point data for the United States were obtained from the U.S. EIA online database for 2016 (EIA, 2016). Natural gas storage geolocations and spatial extent data were obtained using oil field extents from the California Department of Conservation's Division of Oil, Gas, \& Geothermal Resources (DOGGR) for 2016 (DOGGR, 2016). The EPA FLIGHT tool was also used for data quality assurance (EPA, 2015).

Data processing, validation and limitations. Point locations for natural gas storage from EIA in 2016 included 415 points for the entire United States, three of which are in SoCAB. Since underground natural gas storage in California is done in depleted oil fields (EIA, 2008), we determined natural gas storage field extents using the 2016 DOGGR dataset, which contained 516 polygon features for oil field extents in the State of California. The EIA metadata contained operation metrics for each storage field, which we appended to the DOGGR polygon shapefiles for these three extracted entries. The EPA FLIGHT online GHG reporting tool was used to validate the geolocations of the Aliso Canyon and Honor Rancho storage facilities. Southern California Gas Company's online information on natural gas storage facilities validated the geolocation and extent of the Playa Del Rey storage facility.

We did not include former gas storage fields that are no longer used, such as the Montebello Oil Field. Nevertheless, it is possible that these former storage facilities are still leaking, as it takes many years to deplete the gas to pre-storage conditions (Chilingar and Endres, 2005).

Results. The Vista-LA natural gas storage field polygon layer, shown in Figs. 2 and 3, contains the spatial information and attribute information of the three natural gas storage facilities located within SoCAB: Aliso Canyon, Honor Rancho, and Playa Del Rey. The final Vista-LA layer contains metadata relating to field type, company name, amount of base gas, working capacity, field capacity, maximum delivery, and recalculated locational coordinates along with validation notes including any changes made and date of last update.

\section{Natural gas processing plants (Vista-LA layer)}

Data sources. Natural gas processing plant (IPCC - 1B2) geospatial data were obtained from the U.S. Energy Information Administration (EIA) online database for the year 2014 (EIA, 2016).

Data processing, validation and limitations. The raw 2014 EIA dataset contained point geolocations for 551 processing plants across the United States, with six of these in SoCAB, which were georeferenced. Because the raw EIA dataset was limited to a scale of $1: 1000000$, extensive manual geolocation and validation had to be completed for each plant. EIA's geolocation was manually augmented using aerial imagery, planning documents and environmental assessment reports related to the operating companies of each processing plant. Exact spatial extents for the processing plants were created by identifying infrastructure features such as electrical equipment, piping, vents, smoke or steam stacks with towers, racks, and transformers using both Google Earth and Esri Basemap imagery.

Results. The Vista-LA natural gas processing plant layer contains verified geolocated polygons of six facilities located in 
SoCAB. The spatial distribution of the Vista-LA natural gas processing plant layer is shown in Figs. 2 and 3. The associated metadata include information on facility and operator name, plant flow in million cubic feet per day, dry storage in million metric standard cubic feet, energy content of natural gas in British thermal units, barrels of liquid natural gas stored at each facility, recalculated locational coordinates of each polygon, along with validation notes including any changes made and date of last update.

\section{Oil and gas wells (Vista-LA layer)}

Data sources. Data on oil and gas wells were collected from DOGGR for the year 2016 (DOGGR, 2016). The oil and gas well dataset contains information on well status, type, coordinates, and whether it has undergone hydraulic stimulation treatment. Another dataset from DOGGR also includes historical production and injection statistics, owner and operators of the well, and the state of the well.

Data processing, validation and limitations. Due to the sheer size of the datasets (i.e., 32537 oil and gas wells), we assumed the locations of the wells in the DOGGR dataset to be valid for the purposes of this study. Validation of this dataset is beyond the scope of this work, even in cases where manual visual inspection methods and/or automated feature extraction from aerial imagery might be useful. We discuss possible methods for automated feature extraction using aerial imagery further in Sect. 6.4.

According to DOGGR, GIS data for oil and gas wells vary in accuracy, scale, origin and completeness (DOGGR, 2016). DOGGR uses a variety of sources to establish well locations. These sources include handheld measurements using GPS units derived from DOGGR Division staff, coordinates provided by operators, well summary reports, official notices regarding the intent to drill, coordinates derived from aerial imagery, coordinates generated from a tool in MapInfo based on corner call locations, and coordinates from digitized maps. However, we note that some wells in LA were drilled before accurate records were kept by DOGGR (Chilingar and Endres, 2005).

Results. In SoCAB, the Vista-LA oil and gas well dataset includes 32537 oil and gas wells from the 2016 DOGGR dataset (Figs. 2 and 3), associated with activities such as gas storage, pressure maintenance, water disposal, and other (DOGGR, 2016). Specifically, the associated metadata include information such as coordinates, well status, well type, date when drilling commenced, date when well was abandoned, and whether a well undergoes hydraulic fracturing. The dataset includes 5804 abandoned wells, some of which may be located underneath buildings and other structures which hinder validation of their locations (Chilingar and Endres, 2005).

\section{Agriculture, Forestry, and Other Land Use (IPCC Level 1 - Category 3)}

In the California GHG Inventory, emissions from Livestock (IPCC Category 3A) are the largest of the IPCC Level 3 categories (Fig. 1). Emissions from Biomass Burning (IPCC $3 \mathrm{C} 1$ ) contribute at the $\sim 0.1 \%$ level (Fig. 1), and are therefore considered negligible for the purposes of this study. Emissions from Wetlands (IPCC - 3B4) and all other emissions from the Land (IPCC Category 3B), Aggregate Sources and Non- $\mathrm{CO}_{2}$ Emissions (IPCC Category $3 \mathrm{C}$ ) and Other (3D) source types of the Agriculture, Forestry and Other Land Use category are also considered insignificant in the domain, and were not included as part of this study. Within the Livestock category, dairies and cattle farms are the major contributors in the SoCAB region (Viatte et al., 2017). Below we describe our methods for collecting GIS data related to these activities within SoCAB.

\subsection{Livestock (IPCC Level 2 - 3A)}

The livestock category (IPCC $-3 \mathrm{~A}$ ) includes emissions from enteric fermentation (IPCC - 3A1) and manure management (IPCC - 3A2). Manure management systems vary from facility to facility and broadly fall into dry and wet management practices (Kaffka et al., 2016). Manure can be handled and stored using dry lots, deep pits, solid manure storage, daily spread, digesters (CARB, 2016). In slurry/liquid systems, waste from feedlots and other livestock areas is washed and collected in ponds, which are commonly referred to as anaerobic lagoons (Kaffka et al., 2016). Wet manure management involves washing of feedlots and other livestock areas, and the waste runoff is typically collected in lagoons where $\mathrm{CH}_{4}$ is produced due to anaerobic conditions. By contrast, dry manure management practices do not wash waste with water, thus reduce anaerobic conditions. Dairies in So$\mathrm{CAB}$ primarily use dry manure management practices due to the copious amounts of water needed in wet manure management practices for the collection, movement and storage of animal wastes. However, recent mobile measurement campaigns verified $\mathrm{CH}_{4}$ emissions from a small number of dairies with anaerobic lagoons as recently as 2015 (Hopkins et al., 2016b; Viatte et al., 2017). In addition to dairy locations, the locations of some anaerobic lagoons were identified as part of the Vista-LA database as described below.

\subsubsection{Enteric Fermentation (IPCC Level 3-3A1)}

Dairies (Vista-LA layer)

Data sources. Dairy and cattle farm facility data were collected from the California Regional Water Quality Control Board (RWQCB), Santa Ana Region. The data were drawn from annual reports, which contain information on the location of each dairy, the number and type of the herd (i.e., milking cow, dry cow, heifer or calf) and other livestock located 
at each facility for the year 2015 (Edward Kashak, personal communication, 2016). We defined cattle farms as facilities that did not contain any milking cows. Overall, dairy facilities were primarily found to be located in the Chino and San Jacinto basins.

Data processing, validation and limitations. First, the raw RWQCB dataset was georeferenced to match the spatial information of the datasets in Vista-LA. Next, all 110 locations of dairies and cattle farms were validated with Google Earth's historical imagery tool for the year 2015. Facility addresses and coordinates were used to validate the true locations of the farms. When verifying with aerial imagery, focus was given to dairy/cattle facility infrastructure such as feedlots, manure lagoons, animal housing structures, and open pastures. The dairy and cattle farm locations were deemed accurate if the geographic location in the RWQCB dataset was confirmed with aerial imagery and the coordinates did not overlap another facility. During processing and validation, we identified and manually corrected the locations for two farms with incorrect addresses based on aerial imagery. Additionally, we corrected geolocations for twelve farms that were located incorrectly in the original RWQCB dataset using Google Earth aerial imagery and the facility address information given in the RWQCB dataset.

The RWQCB did not report the quantity of feedlots or manure lagoons per dairy, but did include several other types of information which will be useful for estimating emissions from manure management, including annual manure produced, manure hauled, manure spread to cropland and amount of wastewater produced. The RWQCB dataset also contained several facilities that were neither dairy nor cattle farms, such as a livestock market and beef packing facilities. We removed these from the final Vista-LA layer because we do not expect significant $\mathrm{CH}_{4}$ emissions from these facilities.

It was difficult to obtain spatial extents for each facility because they were difficult to differentiate using available imagery. For this reason, all final dairy/cattle facility locations are point-based in the Vista-LA database. The RWQCB database did not report the number of milking cows, dry cows, heifers or calves for the seven of the farms in Chino. While it does not affect the geolocation in our facility maps, information on cattle populations specific to these farms will be helpful for estimating $\mathrm{CH}_{4}$ emissions from these facilities.

Results. The final Vista-LA dairy layer, shown in Figs. 2 and 4, contains a total of 110 livestock facilities in SoCAB: 22 dairies and one cattle farm in the San Jacinto Basin; and 56 dairies, 26 cattle farms and five other livestock farms in Chino. Locations for all facilities were validated using Google Earth imagery. Validation notes have been appended to the spatial dataset for further information on which facilities were corrected for location.

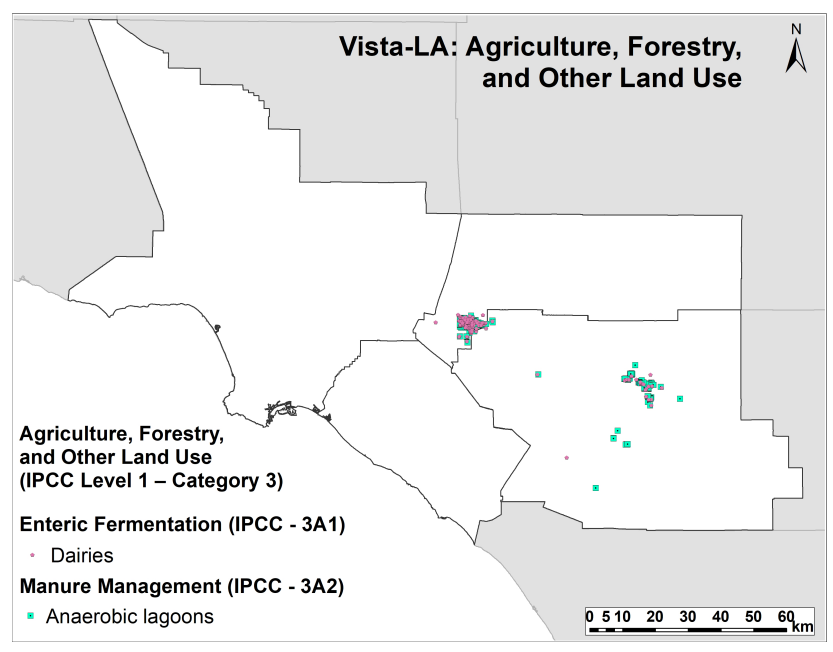

Figure 4. Agriculture, Forestry, and Other Land Use (IPCC Level 1 - Category 3). Spatial distribution of dairies and their respective manure lagoons in SoCAB, encompassing enteric fermentation and manure management $\mathrm{CH}_{4}$ sources. The largest clusters of dairies are located in the Chino and San Jacinto regions, with 110 dairies. San Jacinto Basin was home to 22 dairies and one cattle farm and Chino housed 56 dairies, 26 cattle farms and 5 other livestock farms in the year 2015. About 228 anaerobic lagoons were identified in these two clusters.

\subsubsection{Manure Management (IPCC Level 3 - 3A2)}

\section{Anaerobic lagoons (Vista-LA layer)}

Data sources. In terms of manure management practices, Vista-LA focused on the collection of GIS structures for wet manure management. Specifically, anaerobic lagoons (IPCC - 3A2) were identified using visual inspection of aerial imagery since publicly available GIS datasets on anaerobic lagoons were not available. Therefore, we created a preliminary geospatial dataset of anaerobic lagoons based on GIS data of dairies and cattle farms. Anaerobic lagoons, also commonly called manure lagoons, are considered sub-facility infrastructure within dairy/cattle farms.

Data processing, validation and limitations. Point locations of manure lagoons at each dairy farm were visually determined using aerial imagery from the National Agriculture Imagery Program (NAIP) and Google Earth's Time Tool for the year 2015. Anaerobic lagoons were identified near a dairy/cattle farm facility by their distinct rectangular shape and brown to dark blue color associated with the color of wash water from manure waste. Often, aerial imagery showed evidence of cattle, further confirming the facility location. Once a lagoon structure was identified, GIS processing tools were used to create point data for the geolocation.

Most anaerobic lagoons in SoCAB were found in the Chino/Ontario region, the area with the densest clusters of 
dairy farms. However, the identified geolocation of lagoons for year 2015 is likely to change in the near future due to rapid land-use developments in the region and fluctuating manure management practices (Hirsch, 2006). Further work could be done with automated feature extraction with contemporaneous imagery, as discussed in Sect. 6.4.

Results. The Vista-LA layer for anaerobic lagoons contains 228 point locations in the Chino, Ontario, and Riverside regions, as shown in Figs. 2 and 4. The final layer includes geolocations given by latitude and longitude with validation notes including any changes made and date of last update.

\section{Waste (IPCC Level 1 - Category 4)}

\subsection{Solid Waste Disposal (IPCC Level 2 - 4A)}

Solid waste disposal includes both managed and unmanaged waste disposal sites, as well as uncategorized disposal sites. The largest $\mathrm{CH}_{4}$ emissions are expected from managed waste disposal sites, hence the site category we included in the Vista-LA data product.

\subsubsection{Managed waste disposal (IPCC Level 3 - 4A1)}

Managed waste disposal (IPCC - 4A1) is the third largest IPCC Level 3 emissions source in the California GHG Inventory, trailing only the Enteric Fermentation (IPCC - 3A1) and Manure Management (IPCC - 3A2) categories. For VistaLA, we define managed waste disposal locations as landfills (i.e., solid waste disposal sites and solid waste landfills). Vista-LA includes both active and inactive landfills, with the status recorded in the metadata.

\section{Landfills (Vista-LA layer)}

Data sources. The Vista-LA layer for landfills (IPCC 4A1) was created using landfill data from California's Department of Resources Recycling and Recovery's (CalRecycle) Solid Waste Information System (SWIS) and CARB (CARB, 2014; CalRecycle, 2015). A list of methanegenerating landfills in California was obtained from the 2014 CARB emissions dataset (Larry Hunsaker, personal communication, 2016). Geolocation and spatial extent for each individual landfill facility in SoCAB were generated and verified using the 2005 and 2012 SCAG land-use dataset, Google Earth, and Esri Basemap aerial imagery (see http://gisdata.scag.ca.gov/Pages/GIS-Library.aspx).

Data processing, validation and limitations. The CARB 2014 landfill dataset contained locational records for 372 potential methane-producing landfills for the State of California, with 73 of those landfills located in SoCAB. The CalRecycle/SWIS point dataset contained information on 3087 landfills for all of California, with 759 in SoCAB. CalRecy- cle landfills located in SoCAB were queried to isolate only the 353 tagged as "solid waste disposal facilities" or "solid waste landfills". Finally, 19 duplicate entries were identified and removed.

The geolocation and spatial extent of the 334 unique landfills in the CalRecycle/SWIS dataset were verified using the SCAG 2005 and SCAG 2012 land-use datasets. We used SCAG land-use code 1432 (solid waste disposal facilities) to identify the polygon features associated with active dumps and sanitary landfill operations. We used both SCAG 2005 and SCAG 2012 for the maximum amount of information on landfill extent information because neither SCAG dataset contained all landfill locations. In the raw SCAG 2005 dataset, there were 247 individual polygons associated with land-use code 1432 in SoCAB. The SCAG 2005 dataset showed multiple polygon features for the same facility in some cases, so this dataset was further refined by merging multiple polygons that comprise a known facility location based on the refined CalRecycle/SWIS dataset. Simplified polygon features were created for all the distinguishable solid waste disposal sites based on cross-checking the SCAG dataset with the point data from CalRecycle and World Imagery. In Los Angeles County, the total of 86 polygons associated with land-use code 1432 were aggregated into 18 individual landfills; in Orange County, 60 polygons were aggregated into 7 individual landfills; in Riverside County, 61 polygons were aggregated into 13 individual landfills; and in San Bernardino County, 40 polygons were aggregated into 10 individual landfills. This process was again repeated using the SCAG 2012 dataset that had 211 polygons designated as land-use code 1432. Overall, 48 landfills of the total 334 were identified from the intersection of SCAG 2005/2012 solid waste disposal facilities and landfills from the CalRecycle/SWIS dataset.

The location and spatial extent of the remaining 286 landfills from the CalRecycle/SWIS dataset had to be manually validated and/or generated using Google Earth Imagery along with other GIS methods including geoprocessing and digitizing. We were able to verify the location of 188 out of the 286 designated landfills. Unfortunately, their extent and shape could not be determined using imagery since they had long been closed and thus modified or built upon significantly. A placeholder polygon was generated indicating the historical location with extent and shape determined and digitized using Google Earth imagery (for example canyons, excavated pits, and barren land). However, land-use changes that occur on surfaces of former landfills vary from site to site. As seen with verification procedures for power plants, time-sensitive imagery is critical when evaluating the existence and geolocations of landfills. Using the CalRecycle/SWIS metadata for address location for enhanced verification proved to be difficult because often there were no landfill-related features at these addresses, requiring manual geolocation and correction. 


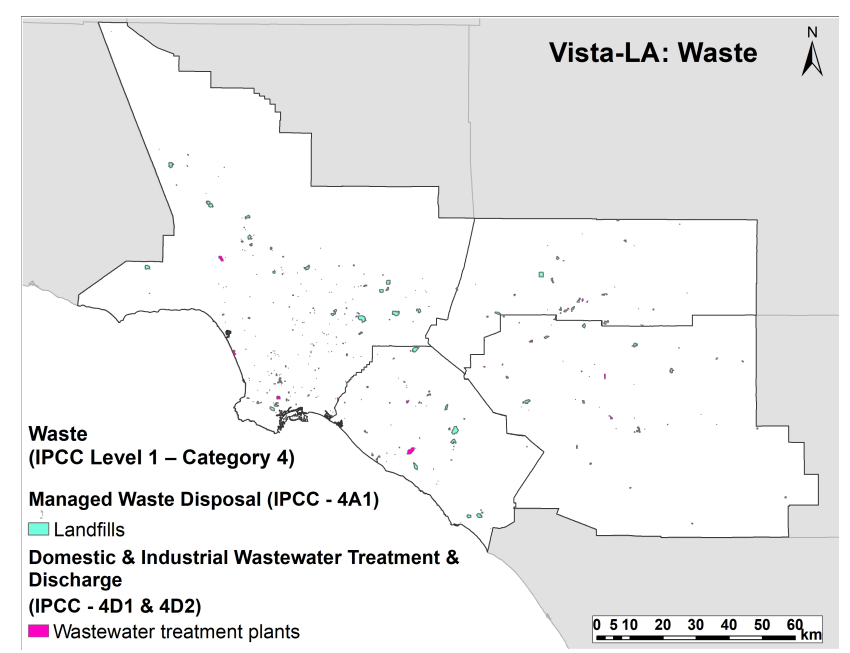

Figure 5. Waste (IPCC Level 1 - Category 4). Spatial distribution of 73 landfills and 26 wastewater treatment plants in SoCAB.

The verified 334 polygons were subset by matching the SWIS number in the CalRecycle metadata to the SWIS number of the 73 potential methane-producing landfills in the CARB dataset in order to produce the final Vista-LA dataset.

Results. In total, 73 potential methane-producing landfills were identified, all locations verified, and polygons were generated in the final dataset using the actual extent or placeholder if extent could not be verified. The final Vista-LA landfill layer is shown in Figs. 2 and 5. The metadata from the CalRecycle/SWIS dataset were appended to the final VistaLA landfill polygon dataset. This includes site-specific information, such as throughput, capacity, and waste types (CalRecycle, 2015). Validation notes include whether facility extent was derived from SCAG 2005, SCAG 2012, or Google Earth imagery. The final polygon data for landfill extents can be separately categorized by landfill status: active, closed, clean-closed, closing, absorbed, and inactive. The operation status breakdown is as follows: 2 were absorbed, 17 were active, 3 were clean-closed (site is considered to cease to exist as a solid waste disposal site, but records are kept to document the status of the site), 308 were closed, 1 was closing, and 3 were inactive.

\subsection{Wastewater Treatment and Discharge (IPCC Level 2 $-4 \mathrm{D})$}

Wastewater treatment and discharge include both domestic and industrial wastewater treatment facilities (Table 1).

\subsubsection{Domestic and Industrial Wastewater Treatment and Discharge (IPCC Level 3-4D1 and 4D2)}

Wastewater treatment in SoCAB is primarily done through aerobic sludge digestion, which has no associated $\mathrm{CH}_{4}$ emissions in the California GHG Inventory (CARB, 2016). However, under low oxygen conditions, $\mathrm{CH}_{4}$ may be emitted as a by-product of enhanced denitrification present in water recycling systems (e.g., open tanks in treatment facilities; Townsend-Small et al., 2012). Many wastewater treatment plants also use anaerobic digesters which collect $\mathrm{CH}_{4}$ for eventual combustion, but may have fugitive $\mathrm{CH}_{4}$ emissions. Of the urban sources of $\mathrm{CH}_{4}$, this source is perhaps the most uncertain (Hopkins et al., 2016a). For the purposes of this study, we assume $\mathrm{CH}_{4}$ emissions are most likely to arise from the plants with the largest daily flow capacity; however, emissions could also potentially arise from various points of collection and/or drainage of wastewater and sewage.

\section{Wastewater treatment plants (Vista-LA layer)}

Data sources. The final Vista-LA wastewater treatment plant layer (IPCC - 4D1 and 4D2) relies on wastewater treatment plant data derived from the State Water Resources Control Board (SWRCB) Regulated Facility Report (SWRCB, 2016), SCAG 2005 and 2012 land-use datasets, and Google Earth and Esri Basemap aerial imagery. The Vista-LA wastewater treatment plant dataset provides accurate location, extent, and facility-level metrics for the largest domestic wastewater treatment plants in SoCAB.

Data processing, validation and limitations. Information for wastewater treatment plants in the LA Basin was obtained from the SWRCB for 2016, including facility names, addresses, coordinates, and the design flow rate in million gallons per day. The raw data contained information on 152 plants for the State of California, 36 of which were located within SoCAB, and 26 of which contained design flow metrics. We geocoded the CARB data as points, and found many uncertainties in the geolocation of wastewater treatment plants in the original dataset. Because of the relatively small number of plants with metrics in SoCAB, we were able to successfully resolve this uncertainty.

We generated polygons and validated plant geolocation for the 26 wastewater treatment plants in SoCAB using Google Earth and Esri Basemap aerial imagery and SCAG 2005 and 2012 land-use data. SCAG data were used to first obtain facility spatial extents. SCAG land-use code 1433 ("liquid waste disposal facilities") was used to verify locations and determine the spatial extent of the original list of wastewater treatment plants. In total, 189 polygons were classified with this land-use code; 44 of those polygons were directly matched with point locations from the SWRCB dataset. Since some facilities had multiple polygons associated with them, they had to be manually merged in order to asso- 
ciate one polygon with one wastewater treatment facility. After this merging procedure, 44 polygons were merged to 11 polygons that directly matched the location of 11 wastewater treatment plants. Polygons for the other 15 plants were digitized using both Google Earth and Esri Basemap imagery as a reference for spatial extent. Each of the 26 plants was successfully validated using aerial imagery. During the manual validation procedure, attention was given to identifying features such as spreading grounds, aeration fields, water injection plants, and circular tanks. EPA Facility Registry Service data for the year 2013 were used as a verification source and contain information about wastewater treatment plants operating within petroleum refineries and power plants (U.S. Environmental Protection Agency, 2016).

The 10 additional plants from the SWRCB dataset were not included in the final Vista-LA dataset because they did not contain facility-level metrics and design flow rates, only location information. Additionally, it is difficult to identify sub-facility plant infrastructure since aerial imagery can only provide a certain degree of context.

Results. The final Vista-LA wastewater treatment plant layer contains geolocations for 26 wastewater treatment plant facilities, as shown in Figs. 2 and 5. Five of these wastewater treatment plants were found to be co-located with power plants. The metadata contain information about the station name, design flow rate metrics, re-calculated location coordinates for each facility, and validation notes including any changes made and the date of last update.

\section{Discussion}

\subsection{Vista-LA data summary}

The Vista-LA database consists of 33354 individual features as points, lines and polygons among thirteen spatial layers, providing a spatial representation of major $\mathrm{CH}_{4}$ production sources in SoCAB (Fig. 2). Pipelines are represented as lines, and oil and gas wells are represented as points, which we consider to be the most accurate representation of these sources. Nine source types are represented as polygons; some represent "area" sources, such as landfills, while others represent a combination of point sources within a facility, such as oil refineries. We have chosen to represent both types of sources with polygons, since Vista-LA is a facility-level database; at present, we do not include sub-facility scale information. These polygons depict the true spatial extent of each facility, enabling improved, and potentially automated attribution of methane plumes observed in airborne imaging or mobile in situ surveys. In survey data, observed methane plumes may not be close to point representations of the address of a facility, and hence may not be easily attributed to the emitting facility, particularly in complex surroundings with many closely located facilities such as SoCAB (e.g., El Segundo or Port of Los Angeles/Long Beach areas). Polygon representations enable an automated workflow where the geolocation of a plume detection is attributed to an entity in the Vista-LA database of sources using spatial intersection without any manual work by a human operator. Source attribution to the facility level is also useful because emissions data are often reported as an aggregate value representing the facility level (e.g., CARB's Mandatory GHG Reporting Regulation). The remaining two sources currently represented by points dairies and anaerobic lagoons - require future work to accurately describe their spatial extents.

The maps in Figs. 3-5 show the spatial distributions of potential sources of $\mathrm{CH}_{4}$ in the IPCC Level 1 categories: Energy (1), Agriculture (3), and Waste (4), respectively. The highest density of $\mathrm{CH}_{4}$-emitting infrastructure is located in the western portion of SoCAB in Los Angeles and Orange counties (Fig. 2). The Energy sector, specifically oil and gas wells, accounts for the majority of the spatial inventory (32537 features) and is primarily located in southern and northwestern Los Angeles County and northern Orange County (Fig. 3). The Agriculture sector is dominated by dairies and cattle farms located in the Chino and San Jacinto basins of San Bernardino and Riverside counties (Fig. 4). By contrast, landfills and wastewater treatment plants are relatively evenly distributed throughout SoCAB (Fig. 5).

In total, Vista-LA polygons cover $117 \mathrm{~km}^{2}$, or $0.68 \%$, of the $17108 \mathrm{~km}^{2}$ extent of SoCAB, substantially narrowing the area over which surveys for fugitive and non-inventoried $\mathrm{CH}_{4}$ sources should be carried out. This spatial structure more closely matches the "hotspot" nature of atmospheric $\mathrm{CH}_{4}$ that has been observed in SoCAB on the scale of meters to kilometers (Hopkins et al., 2016b) than is represented by current existing products that are too coarse to capture the fine-scale nature of $\mathrm{CH}_{4}$ hotspots in urban areas.

\subsection{Vista-LA data completeness and uncertainty}

The goal of Vista-LA is to provide a complete representation of potential anthropogenic $\mathrm{CH}_{4}$ emissions sources in SoCAB; however, ensuring complete spatial coverage of important $\mathrm{CH}_{4}$ sources is challenging. We made the simplifying assumption that including the eight IPCC Level 3 sources which constitute $\sim 99 \%$ of the expected California GHG Inventory emissions would capture the most important $\mathrm{CH}_{4}$ sources in SoCAB, omitting rice cultivation, imported electricity, and coal mining, which are not present in the domain (see Fig. 1). We also added two new source types that are not included in the California GHG Inventory: compressed natural gas (CNG) fueling stations (total: 109 locations) and liquefied natural gas (LNG) fueling stations (total: 27 locations; see Table 1 and Table S1 in the Supplement). While these sources are not presently included in the inventory, there was sufficient evidence for fugitive $\mathrm{CH}_{4}$ emissions to include them in Vista-LA (e.g., Fig. 8; Clark et al., 2017; Hopkins et al., 2016b), particularly given that SoCAB con- 
tains 32 and $57 \%$ of the state's CNG and LNG fueling stations, respectively.

We verified our list of included source categories against the key source categories at the national level from the U.S. EPA inventory (EPA, 2016). Although rice cultivation and coal mining contribute $>1 \%$ to total U.S. methane emissions, these are not significant sources of methane in So$\mathrm{CAB}$ and were excluded from the Vista-LA database. We also compared Vista-LA's source categories to observations of $\mathrm{CH}_{4}$ hotspots in Los Angeles. The known sources of enhanced $\mathrm{CH}_{4}$ levels - landfills, cattle, water treatment, power plants, CNG fueling, natural gas pipelines, oil refineries, and oil fields - corresponded to Vista-LA layers with the exception of geologic seeps (Hopkins et al., 2016b). This correspondence suggests that Vista-LA is well suited for source attribution of anthropogenic $\mathrm{CH}_{4}$ hotspots in SoCAB.

We omitted several categories that might have important contributions to $\mathrm{CH}_{4}$ emissions in SoCAB, such as transportation. Although transportation produces $\sim 1 \%$ of California inventoried $\mathrm{CH}_{4}$ emissions (and $<0.3 \%$ of national emissions; EPA, 2016), it likely comprises a greater fraction of SoCAB emissions given the greater density of traffic in the region. We have chosen not to include a spatial layer for transportation in this version of Vista; we view Vista primarily as a tool for attribution of large fugitive $\mathrm{CH}_{4}$ emissions sources, and there is no evidence for this type of emission from conventionally fueled vehicles. Fugitive $\mathrm{CH}_{4}$ emissions detected along roadways are more likely to originate from leaks in natural gas pipelines that lie underneath the road surface (Chamberlain et al., 2016). Adding a spatial layer for transportation would be simple to achieve, such as by including a map of the road network or from an existing highresolution inventory such as Hestia (Rao et al., 2017), and needs to be included in an emissions inventory.

We also omitted two possible natural sources of $\mathrm{CH}_{4}$ emissions in SoCAB - geologic seeps and wetlands - because they are not considered sources in the most recent version of the California GHG Inventory (geologic seeps are inventoried as "excluded" sources). These sources have not been included in this version of Vista despite the large observed emissions from geologic seeps in SoCAB (Farrell et al., 2013). We have identified possible spatial datasets to include in future versions of Vista (USGS maps of Natural Oil and Gas Seeps in California, https://walrus.wr.usgs.gov/seeps/ and U.S. Fish and Wildlife Service National Wetlands Inventory, https://www.fws.gov/wetlands/). There is a potential that either sources may contribute significantly to the SoCAB emissions budget - we anticipate including these in future versions.

There is also uncertainty in the spatial representation of sources in Vista-LA. We assumed the spatial location of sources by linking facility-level (or pipeline-, or oil welllevel) datasets to IPCC source categories (Table 1), although there may not be a perfect correspondence between mappable infrastructure and these sources. An alternative ap- proach would have been to map out the lifecycle of each IPCC Level 1 sector (e.g., Energy, Agriculture, Waste), and determine spatial locations of each lifecycle phase in the domain. We chose the IPCC approach because it is more standardized, and hence applicable to other cities. The lifecycle approach requires local knowledge, and is likely to differ among cities and regions (Hopkins et al., 2016a). We also assumed that most $\mathrm{CH}_{4}$ emissions come from the main facility associated with an emitting activity, such as wastewater treatment plants for wastewater emissions, rather than the sewer network. This assumption may not hold true, for example when manure is exported from dairies and treated elsewhere. In contrast to waste and agriculture, we included a higher level of detail for the natural gas system because there is more evidence of quantitatively significant $\mathrm{CH}_{4}$ emissions from distributed parts of the network (e.g., pipelines).

Finally, we recognize error inherent in the availability of data, and in the original data sources themselves. Vista-LA relies on publicly available datasets. Consequently, we are constrained by (a) lack of data on some infrastructure types that may be transient or have never been collected, such as the locations of manure piles; (b) unavailability of proprietary data, such as the locations of petroleum storage tanks or gathering pipelines; and (c) data that pose a security risk, and hence cannot be distributed, such as specific locations of natural gas compressor stations and high-pressure transmission pipelines. Within the datasets themselves, we found errors in geolocation and missing facilities. As described in the text, we took steps to control these errors inherent to the source datasets by performing visual validation and using multiple datasets for the same source category. In most original datasets, geolocation of some facilities was incorrect by up to several kilometers for various reasons, and some geolocations corresponded to the offices or street address of facilities rather than actual facility location (e.g., for dairies). Raw datasets for landfills, natural gas processing plants, and wastewater treatment plants also had a coarse spatial resolution resulting in uncertain geolocations, which we corrected. However, we were unable to visually validate all sources, including oil and gas wells, natural gas pipelines, and landfills.

With respect to omission of $\mathrm{CH}_{4}$-emitting facilities, in many cases, the total number of facilities varied among the raw datasets that were used to construct the Vista-LA layers (e.g., landfills, natural gas processing plants, natural gas storage fields, power plants, CNG and LNG fueling stations, and wastewater treatment plants). For power plants, there are many small facilities in California (around 4020 plants) that are not included in the EIA dataset (110 plants). Overall, these small power plant facilities only represent about $3 \%$ of the total statewide electricity production related to fossil fuel $\mathrm{CO}_{2}$ emissions, and therefore most are not tracked. Some of these facilities are also not grid-tied, but are facilities that generate electricity for an industrial process (Kevin Gurney, personal communication, 2017). We found that at least nine power plants were located within the bounds of a petroleum 


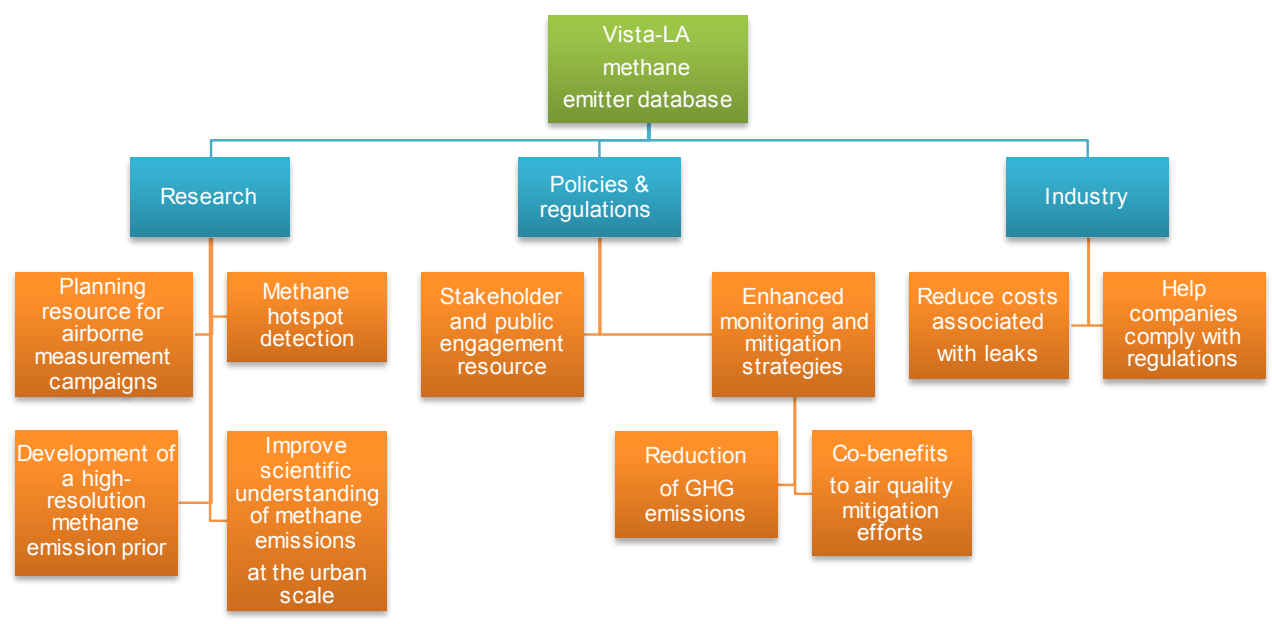

Figure 6. Overview of applications of the Vista- $\mathrm{LA} \mathrm{CH}_{4}$ emissions mapping database. Vista-LA can provide numerous applications and benefits to research, policy, and industry.

refinery facility in SoCAB. We have not considered potential emissions from smaller facilities or those contained within other facilities, but this may be important to consider as part of future work.

\subsection{Vista-LA applications}

At present, Vista-LA does not contain the bottom-up empirical measurements required for the creation of an accurate fine-scale $\mathrm{CH}_{4}$ inventory (as in Lyon et al., 2015). However, making and interpreting atmospheric $\mathrm{CH}_{4}$ measurements is easier for the dense, heterogeneous landscape of SoCAB with the guidance of the Vista-LA spatial layers. Vista-LA represents a much-needed first step towards the development of a fine-scale urban $\mathrm{CH}_{4}$ emissions inventory that can be used for design and interpretation of $\mathrm{CH}_{4}$ hotspot surveys. Importantly, Vista-LA complements the tiered remote sensing observation strategies for regional top-down $\mathrm{CH}_{4}$ emission measurements. Figure 6 summarizes potential applications of Vista-LA, which are described in the following sections.

\subsubsection{Research planning}

Vista-LA is already in use as a planning tool for research aimed at better understanding $\mathrm{CH}_{4}$ emissions in SoCAB, by guiding design of $\mathrm{CH}_{4}$ super-emitter surveys and appropriate selection of locations for stationary $\mathrm{CH}_{4}$ monitoring. Figure 7 shows how Vista-LA has been used for planning airborne remote sensing campaigns to survey $\mathrm{CH}_{4}$ point sources. Guidance from Vista-LA allows airborne campaigns to be designed for maximum coverage of key infrastructure identified in SoCAB. In Fig. 7, aircraft flight lines shown in green illustrate a path optimized for coverage of key $\mathrm{CH}_{4}$ infrastructure in SoCAB.

\subsection{2 $\mathrm{CH}_{4}$ hotspot detection}

In addition, Vista-LA can be used to interpret observations of atmospheric $\mathrm{CH}_{4}$ measurements, addressing the challenge of source attribution of $\mathrm{CH}_{4}$ hotspots detected in airborne and ground-based surveys. Pinpointing the source of fugitive $\mathrm{CH}_{4}$ emissions sources in dense mixed-land-use urban areas has been an ongoing challenge (Cambaliza et al., 2015; Hopkins et al., 2016b). In many urban areas, many potential $\mathrm{CH}_{4}$ sources are located in close proximity, such as in the ports of Los Angeles and Long Beach, which contain extensive fossil fuel use and transportation, active oil drilling and refining, and wastewater treatment. Figure 8 shows an overlay of $\mathrm{CH}_{4}$ observations from a mobile $\mathrm{CH}_{4}$ survey in June 2013, where high-frequency in situ $\mathrm{CH}_{4}$ observations were made from a moving van, as described in Hopkins et al. (2016b). Atmospheric $\mathrm{CH}_{4}$ levels are shown as colored boxes with an " $x$ " in the center, with blue colors representing near-background levels, and warmer colors (red) representing elevated $\mathrm{CH}_{4}$. The same region was flown by the Hyperspectral Thermal Emission Spectrometer (HyTES) in July 2014. Plumes of $\mathrm{CH}_{4}$ were retrieved from HyTES radiance data, and are shown in green (Hulley et al., 2016). In the scene, Vista-LA shows roughly a dozen oil and gas wells and a CNG fueling station near the elevated $\mathrm{CH}_{4}$ observations, narrowing down the number of potential sources greatly. Together with wind direction, these observations plus Vista-LA enable attribution to the facility level.

\subsubsection{Stakeholder and public engagement tool}

Vista-LA also has the potential to guide $\mathrm{CH}_{4}$ mitigation efforts by identifying persistent $\mathrm{CH}_{4}$-emitting infrastructure when combined with atmospheric measurements. In order to control $\mathrm{CH}_{4}$ emissions effectively in cities, it is essential to understand the fine-scale spatial distribution of stationary 


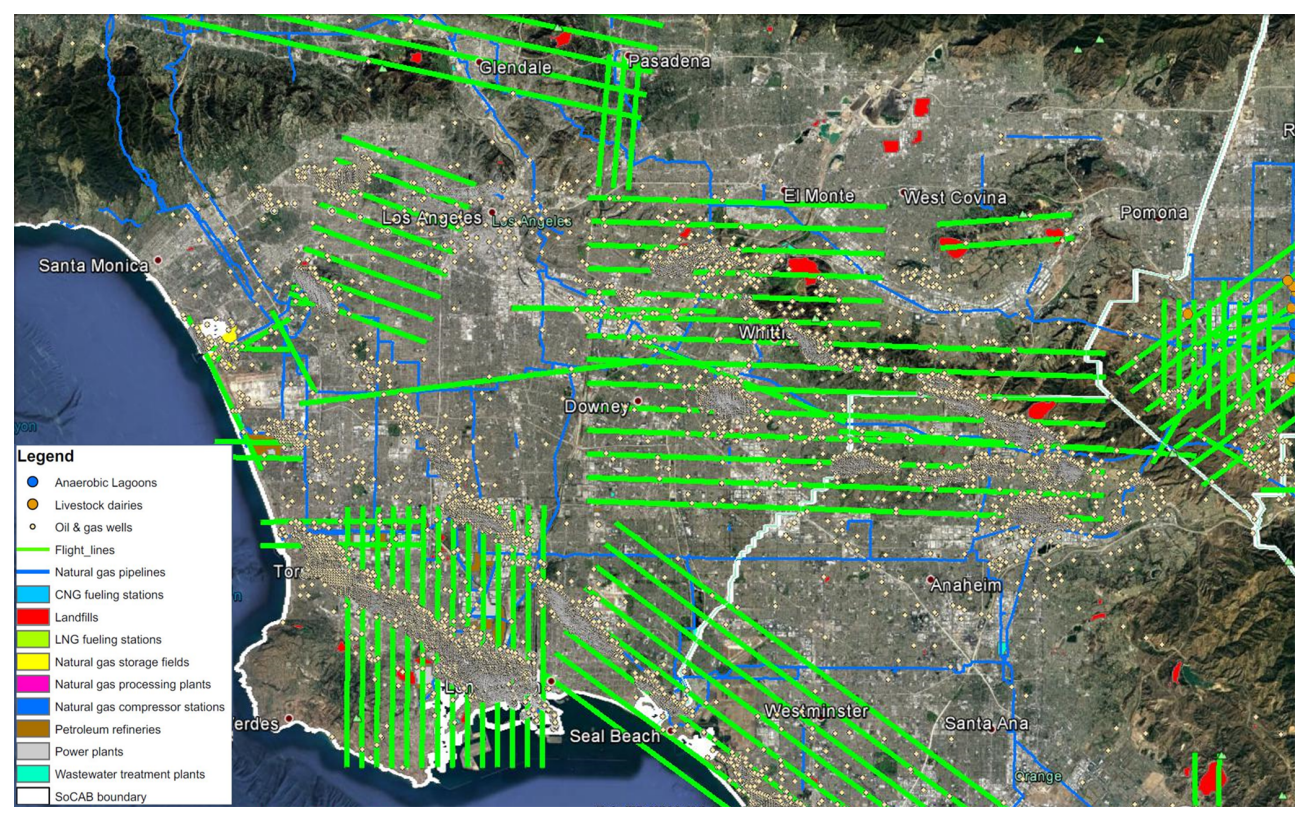

Figure 7. Vista-LA as a flight planning resource. The flight path of an airborne $\mathrm{CH}_{4}$ remote sensing campaign to survey $\mathrm{CH}_{4}$ point source emissions, shown as green lines, was optimized to include $\mathrm{CH}_{4}$-emitting infrastructure for key sources shown in Vista-LA.

sources from a broad range of industries in the energy, agriculture, and waste sectors. Local regulators and city planners may be able to use the location information presented in Vista-LA, combined with targeted surveys or observations, to develop enhanced $\mathrm{CH}_{4}$ monitoring and mitigation strategies for their cities. Vista-LA may also be extensible to airquality mitigation efforts. For example, some processes that emit $\mathrm{CH}_{4}$ also result in co-emission of other gases that are important for climate and air quality. By incorporating new information in Vista-LA, such as information on permitting and/or sub-facility infrastructure information, users may be able to evaluate the air-quality co-benefits associated with fugitive $\mathrm{CH}_{4}$ mitigation strategies.

\subsection{Future directions: Vista $\mathrm{CH}_{4}$ database}

Vista-LA was primarily developed to identify $\mathrm{CH}_{4}$-emitting infrastructure in SoCAB. However, we anticipate that our approach could be scaled to other regions and over larger spatial scales, including the State of California, the contiguous U.S., and possibly internationally. Expanding the VistaLA database across the State of California is highly feasible given that our framework is consistent with how the State of California reports $\mathrm{CH}_{4}$ emissions. Additionally, many of the raw data sources used in the development of Vista-LA already encompass state-level or national-level spatial extents (Table 1). In theory, the approach could also be expanded to any region on Earth, as long as an IPCC (or similar) inventory and geolocation data for the top-emitting sources are publicly available. Our framework is also dependent on the availability of timely, reliable public datasets. In this regard,
Los Angeles and the State of California are perfect testbeds for development. By contrast, many regions may not have such information available publicly, especially in developing nations.

Efforts to expand the database could be enhanced by the use of automated feature extraction techniques. For example, the use of automated feature extraction techniques could expedite the process of identifying, extracting, and updating relevant infrastructure features for estimating emissions, such as those listed in the Supplement, Table S1. Automated feature extraction involves machine-learning algorithms used to recognize patterns through image processing (see, e.g., Yuan, 2016; Castelluccio et al., 2015). In this way, aerial imagery in SoCAB could essentially be used to parse through and locate features such as converted landfills, oil and gas wellheads, anaerobic lagoons, and/or wastewater treatment plants. It is important to note that a machine-learning algorithm may introduce uncertainty more than the use of raw datasets; therefore, efforts need to be made to quantify these uncertainty estimates. Even so, machine-learning algorithms hold the potential to advance the process of identifying infrastructure of potential $\mathrm{CH}_{4}$ sources at a larger scale.

In the future, the information in Vista-LA could be used to generate a high-resolution bottom-up gridded $\mathrm{CH}_{4}$ emissions product for SoCAB. While the initial goal of the VistaLA database was to provide facility location information, some of the facility- and sub-facility-level activity and operation information contained within the metadata may also be useful for assigning emission factors to each source (see Metadata and Supplement, Table S1). For example, the VistaLA dairy layer contains information on herd population by 


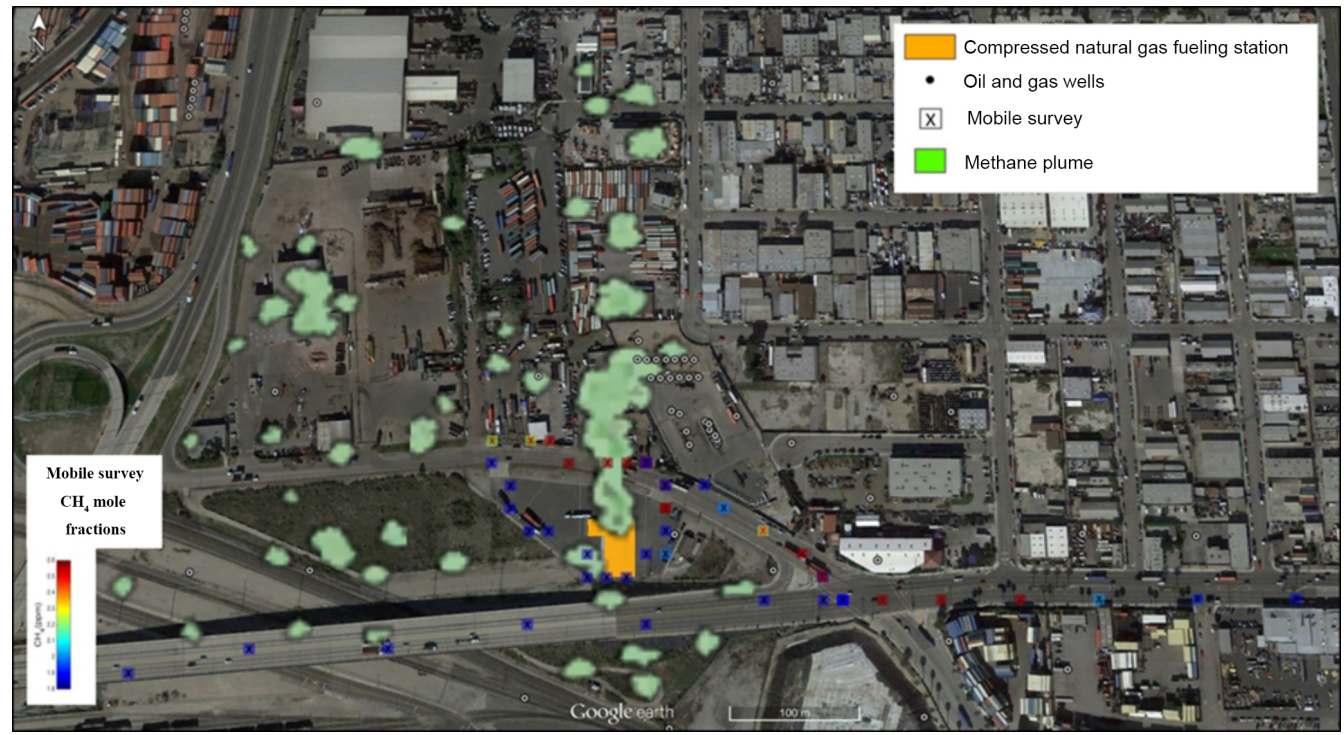

Figure 8. Application of Vista-LA as a tool for source attribution of $\mathrm{CH}_{4}$ hotspots. Vista-LA can be used to determine the source of $\mathrm{CH}_{4}$ hotspots observed during on-road mobile surveys and aircraft campaigns. In this example, Vista-LA layers are shown with $\mathrm{CH}_{4}$ plumes observed by the HyTES airborne imaging spectrometer and elevated atmospheric $\mathrm{CH}_{4}$ levels near the surface from a mobile survey in the port of Long Beach, California. The co-location of the green colored $\mathrm{CH}_{4}$ plume from HyTES (July 2014) and the red point observations of enhanced $\mathrm{CH}_{4}$ levels from the mobile survey (June 2013) suggest that the CNG fueling station, shown by the orange polygon, is the source of the observed $\mathrm{CH}_{4}$ emissions.

type, which could be used to estimate emissions factors for enteric fermentation and manure management. Manure management practices are known to vary widely by region, even within the State of California. Potentially, the information in the Vista-LA database could also be combined with topdown observations and provide independent validation of bottom-up $\mathrm{CH}_{4}$ flux estimates, in a similar approach to that shown in Sect. 6.3.2 and Fig. 8. In general, utilizing the spatial information in Vista-LA to assign $\mathrm{CH}_{4}$ emissions estimates could significantly minimize errors in the spatial representation of sources compared to previous estimates for this region. Updates such as changes to locations, spatial extents, and removal or addition of facilities will be required on at least an annual basis to provide timely and accurate emissions information.

\section{Data availability}

The current releases of the Vista-LA datasets and associated metadata are open access and are available in the Oak Ridge National Laboratory Distributed Active Archive Center for Biogeochemical Dynamics (ORNL DAAC) (Carranza et al., 2018; https://doi.org/10.3334/ORNLDAAC/1525).

\section{Conclusions}

Vista-LA adopts a GIS-based approach to map known or potential $\mathrm{CH}_{4}$ emissions sources in dense-mixed-land-use ar- eas of the South Coast Air Basin, which includes the LA megacity. Characterizing $\mathrm{CH}_{4}$ emissions on the urban scale is incredibly complex, as there exist thousands of structures known to be associated with $\mathrm{CH}_{4}$ emissions. Vista-LA successfully identifies 33554 potential $\mathrm{CH}_{4}$ emitters from three IPCC sectors: Energy, Agriculture, and Waste. Vista-LA contains accurate and validated spatial extent information for nine sources including compressed natural gas fueling stations, liquefied natural gas fueling stations, landfills, natural gas compressor stations, natural gas storage fields, natural gas processing plants, petroleum refineries, power plants, and wastewater treatment plants. It also includes point location of anaerobic lagoons, dairies, and oil and gas wells as well as a natural gas pipeline network for SoCAB. Vista-LA can assist in flight planning for $\mathrm{CH}_{4}$ airborne campaigns and potential $\mathrm{CH}_{4}$ hotspot detection, and can essentially be merged with top-down flux estimates for the identification of individual point sources. In this way, Vista-LA represents a first step towards developing a gridded emissions spatial product that can illustrate spatial distribution of $\mathrm{CH}_{4}$ emissions on a fine scale. By fusing Vista-LA, automated surface feature recognition, and other various remote sensing point source data products, we could dramatically improve the attribution of methane emissions.

Vista-LA serves as a prototype resource to aid in the development of high-resolution bottom-up gridded models of GHG emissions in densely populated urban areas with a complex variety of sources and can be adapted to larger scales in accordance with characteristics innate to each re- 
spective region. The development of spatially resolved carbon emissions datasets can offer significant advances in understanding, managing, and mitigating carbon emissions from cities. Generally, uncertainties in emissions sources and their locations in inventories hinder the implementation of mitigation policies. To be useful, $\mathrm{CH}_{4}$ emissions information is needed on the scale of individual sources. In addition to accurate and timely spatial information, urban $\mathrm{CH}_{4}$ emissions inventories should also be flexible enough to incorporate new information while remaining relevant for observation-based research efforts such as surveys, hotspot detection, and inversion modeling. Finally, the information should be communicated in an open-source, transparent, and well-documented manner. 


\section{Appendix A}

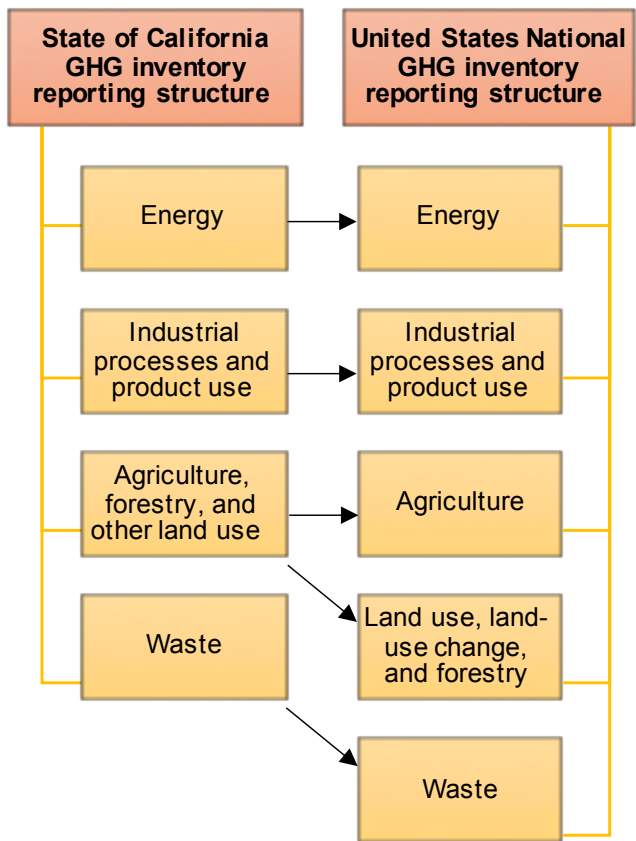

Figure A1. Comparison between GHG emissions inventory reporting structure for the State of California vs. the United States. VistaLA complies with the State of California's GHG emissions inventory structure, but can be adapted to different regions, such as for the national GHG emissions inventory of the United States. Arrows indicate links between sector levels of the two GHG inventories. 


\section{The Supplement related to this article is available online at https://doi.org/10.5194/essd-10-653-2018-supplement.}

Competing interests. The authors declare that they have no conflict of interest.

Acknowledgements. A portion of this research was carried out at the Jet Propulsion Laboratory, California Institute of Technology, under contract with the National Aeronautics and Space Administration (NASA). The NASA DEVELOP program (http://develop.larc.nasa.gov/) provided the primary support for this project for Valerie Carranza and Talha Rafiq during 2015. Isis Frausto-Vicencio also participated in the NASA DEVELOP program and received support from the NASA Scholars Program and the Minority University Research and Education (MUREP) Project during 2014-2016. Francesca M. Hopkins was supported by an appointment to the NASA Postdoctoral Program at the Jet Propulsion Laboratory, California Institute of Technology, administered by the Universities Space Research Association under contract with NASA. Kristal R. Verhulst was supported by the National Institutes of Standards and Technologies (NIST) Greenhouse Gas and Climate Science Measurements Program. The authors are very thankful to Benjamin Holt, Gwen Miller, and Christine Rains from the NASA/JPL DEVELOP program for helpful discussions regarding data analysis, and to $\mathrm{M}$. Limb for comments on the manuscript. We are also thankful for valuable advice and guidance from the California Air Resources Board (ARB) Greenhouse Gas Emission Inventory Branch, including Anny Huang, Larry Hunsaker, Kevin Eslinger, William Widger, Jessica Charrier, and Gabe Ruiz, and Terry Rose, Fui Fang Thong, and Gerry Bemis for assistance with data from the California Energy Commission, and Edward Kashak from the Regional Water Quality Control Board, Santa Ana Region. This paper has used information provided by the California Energy Commission. This paper does not necessarily represent the views of the Energy Commission, its employees, or the State of California. The Energy Commission and the State of California make no expressed or implied warranties, and assume no legal liability for the information contained in this paper.

Edited by: David Carlson

Reviewed by: two anonymous referees

\section{References}

Asefi-Najafabady, S., Rayner, P. J., Gurney, K. R., McRobert, A., Song, Y., Coltin, K., Huang, J., Elvidge, C., and Baugh, K.: A multiyear, global gridded fossil fuel $\mathrm{CO}_{2}$ emission data product: Evaluation and analysis of results, J. Geophys. Res.-Atmos., 119, 17, https://doi.org/10.1002/2013JD021296, 2014.

Brandt, A. R., Heath, G. A., Kort, E. A., O’Sullivan, F., Pétron, G., Joordan, S. M., Tans, P., Wilcox, J., Gopstein, A. M., Arent, D., Wofsy, S., Brown, N. J., Bradley, R., Stucky, G. D., Eardly, D., and Harriss, R.: Methane Leaks from North American Natural Gas Systems, Science, 343, 733-735, https://doi.org/10.1126/science.1247045, 2014.
California Energy Commission (CEC): California Natural Gas Pipeline, available at: https://cecgis-caenergy.opendata.arcgis. com/ (last access: 31 March 2017), 2012.

CalRecycle: SWIS Facility/Site Search, available at: http://www. calrecycle.ca.gov/SWFacilities/Directory/Search.aspx, last access: 31 December, 2015.

Cambaliza, M. O. L., Shepson, P. B., Bogner, J., Caulton, D. R., Stirm, B., Sweeney, C., Montzka, S. A., Gurney, K. R., Spokas, K., Salmon, O. E., Lavoie, T. N., Hendricks, A., Mays, K., Turnbull, J., Miller, B. R., Lauvaux, T., Davis, K., Karion, A., Moser, B., Miller, C., Obermeyer, C., Whetstone, J., Prasad, K., Miles, N., and Richardson, S.: Quantification and source apportionment of the methane emission flux from the city of Indianapolis, Elementa, 3, 37, 2015.

CARB: California's 2000-2012 Greenhouse Gas Emissions Inventory Technical Support Document, State of California Air Resources Board, Air Quality Planning and Science Division, 2014.

CARB: California Greenhouse Gas Inventory for 2000-2013 - by Sector and Activity Electricity Generation (In State) California Greenhouse Gas Inventory for 2000-2013 - by Sector and Activity, 2015.

CARB: Documentation of California's 2000-2015 GHG Inventory - Index, available at: http://www.arb.ca.gov/cc/inventory/ doc/doc_index.php, last access: 10 August, 2016.

Carranza, V., Rafiq, T., Frausto-Vicencio, I., Hopkins, F., Verhulst, K. R., Rao, P., Duren, R. M., and Miller, C. E.: Sources of Methane Emissions (Vista-LA), South Coast Air Basin, California, USA, ORNL DAAC, Oak Ridge, Tennessee, USA, https://doi.org/10.3334/ORNLDAAC/1525, 2018.

Castelluccio, M., Poggi, G., Sansone, C., and Verdoliva, L.: Land Use Classification in Remote Sensing Images by Convolutional Neural Networks, available at: https://arxiv.org/abs/1508.00092 (last access: 20 July 2016), 2015.

Chamberlain, S. D., Ingraffea, A. R., and Sparks, J. P.: Sourcing methane and carbon dioxide emissions from a small city: Influence of natural gas leakage and combustion, Environ. Pollut., 218, 102-110, https://doi.org/10.1016/j.envpol.2016.08.036, 2016.

Chilingar, G. and Endres, B.: Environmental hazards posed by the Los Angeles Basin urban oilfields: an historical perspective of lessons learned, Environ. Geol., 47, 302-317, https://doi.org/10.1007/s00254-004-1159-0, 2005.

Clark, N. N., McKain, D. L., Johnson, D. R., Wayne, W. S., Li, H., Akkerman, V., Sandoval, C., Covington, A. N., Mongold, R. A., Hailer, J. T., and Ugarte, O. J.: Pump-to-Wheels Methane Emissions from the Heavy-Duty Transportation Sector, Environ. Sci. Technol., 51, 968-976, https://doi.org/10.1021/acs.est.5b06059, 2017.

Conley, S., Franco, G., Faloona, I., Blake, D., Peischl, J., and Ryerson, T.: Methane emissions from the 2015 Aliso Canyon blowout in Los Angeles, CA, Science, 351, 1317-1320, https://doi.org/10.1126/science.aaf2348, 2016.

Dlugokencky, E. J., Nisbet, E. G., Fisher, R., and Lowry, D.: Global atmospheric methane: budget, changes and dangers, Philos. Trans. R. Soc. London A Math. Phys. Eng. Sci., 369, 2058 2072, https://doi.org/10.1098/rsta.2010.0341, 2011.

DOE: Alternative Fuels Data Center, available at: http://www.afdc. energy.gov/, last access: 31 March, 2017. 
DOGGR: GIS Mapping, available at: http://www.conservation.ca. gov/dog/maps/Pages/GISMapping2.aspx, last access: 18 June, 2016.

Duren, R. and Miller, C.: Measuring the carbon emissions of megacities, Nat. Clim. Change, 2, 560-562, 2012.

EIA: Office of Oil \& Gas, Natural Gas Division Gas, Gas Transportation Information System, available at: https://www.eia.gov/pub/oil_gas/natural_gas/analysis_ publications/ngpipeline/undrgrndstor_map.html (last access: 31 March 2017), 2008.

EIA: Maps: Layer Information for Interactive State Maps, available at: https://www.eia.gov/maps/layer_info-m.cfm (last access: 31 March 2017), 2016.

EPA: FLIGHT: 2015 Greenhouse Gas Emissions from Large Facilities, available at: https://ghgdata.epa.gov/ghgp/main.do (last access: 18 April 2017), 2015

EPA: Inventory of U.S. Greenhouse Gas Emissions and Sinks: 1990-2014, National Service Center for Environmental Publications, 2016.

European Commission Joint Research Centre: Netherlands Environmental Assessment Agency (2010) Emission Database for Global Atmospheric Research (EDGAR), Release Version 4.2., available at: http://edgar.jrc.ec.europa.eu (last access: 31 March 2017), 2010.

Farrell, P., Culling, D., and Leifer, I.: Transcontinental methane measurements: Part 1. A mobile surface platform for source investigations, Atmos. Environ., 74, 422-431, https://doi.org/10.1016/j.atmosenv.2013.02.014, 2013.

Gioli, B., Toscano, P., Lugato, E., Matese, A., Miglietta, F., Zaldei, A., and Vaccari, F. P.: Methane and carbon dioxide fluxes and source partitioning in urban areas: The case study of Florence, Italy, Environ. Pollut., 164, 125-131, https://doi.org/10.1016/j.envpol.2012.01.019, 2012.

Gurney, K. R., Razlivanov, I., Song, Y., Zhou, Y., Benes, B., and Abdul-Massih, M.: Quantification of fossil fuel $\mathrm{CO}_{2}$ emissions on the building/street scale for a large US city, Environ. Sci. Technol., 46, 12194-12202, https://doi.org/10.1021/es3011282, 2012.

Gurney, K. R., Romero-Lankao, P., Seto, K. C., Hutyra, L. R., Duren, R., Kennedy, C., Grimm, N. B., Ehleringer, J. R., Marcotullio, P., Hughes, S., Pincetl, S., Chester, M. V., Runfola, D. M., Feddema, J. J., and Sperling, J.: Climate change: Track urban emissions on a human scale, Nature, 525, 179-181, https://doi.org/10.1038/525179a, 2015.

Helfter, C., Tremper, A. H., Halios, C. H., Kotthaus, S., Bjorkegren, A., Grimmond, C. S. B., Barlow, J. F., and Nemitz, E.: Spatial and temporal variability of urban fluxes of methane, carbon monoxide and carbon dioxide above London, UK, Atmos. Chem. Phys., 16, 10543-10557, https://doi.org/10.5194/acp-16-105432016, 2016

Hirsch, J.: Dairies Moving Out of Inland Empire, Los Angeles Times, 2006.

Hopkins, F. M., Ehleringer, J. R., Bush, S. E., Duren, R. M., Miller, C. E., Lai, C., Hsu, Y., Carranza, V., and Randerson, J. T.: Mitigation of methane emissions in cities: How new measurements and partnerships can contribute to emissions reduction strategies, Earth's Future, 4, 408-425, https://doi.org/10.1002/2016EF000381, 2016a.
Hopkins, F. M., Kort, E. A., Bush, S. E., Ehleringer, J., Lai, C., Blake, D., and Randerson, J. T.: Spatial patterns and source attribution of urban methane in the Los Angeles Basin, J. Geophys. Res.-Atmos., 121, 2490-2507, https://doi.org/10.1002/2015JD024429, 2016 b.

Hsu, Y. K., VanCuren, T., Park, S., Jakober, C., Herner, J., FitzGibbon, M., Blake, D. R., and Parrish, D. D.: Methane emissions inventory verification in southern California, Atmos. Environ., 44, 1-7, https://doi.org/10.1016/j.atmosenv.2009.10.002, 2009.

Hulley, G. C., Duren, R. M., Hopkins, F. M., Hook, S. J., Vance, N., Guillevic, P., Johnson, W. R., Eng, B. T., Mihaly, J. M., Jovanovic, V. M., Chazanoff, S. L., Staniszewski, Z. K., Kuai, L., Worden, J., Frankenberg, C., Rivera, G., Aubrey, A. D., Miller, C. E., Malakar, N. K., Sánchez Tomás, J. M., and Holmes, K. T.: High spatial resolution imaging of methane and other trace gases with the airborne Hyperspectral Thermal Emission Spectrometer (HyTES), Atmos. Meas. Tech., 9, 2393-2408, https://doi.org/10.5194/amt-9-2393-2016, 2016.

IPCC: Good Practice Guidance and Uncertainty Management in National Greenhouse Gas Inventories, 2001.

IPCC: 2006 IPCC Guidelines for National Greenhouse Gas Inventories, Ch. 4, Table 4.1., 2006.

Jeong, S., Hsu, Y. K., Andrews, A. E., Bianco, L., Vaca, P., Wilczak, J. M., and Fischer, M. L.: A multitower measurement network estimate of California's methane emissions, J. Geophys. Res.Atmos., 118, 11339-11351, https://doi.org/10.1002/jgrd.50854, 2013.

Jeong, S., Newman, S., Zhang, J., Andrews A. E., Bianco, L., Bagley, J., Cui, X., Graven, H., Kim, J., Salameh, P., LaFranchi, B. W., Priest, C., Campos-Pineda, M., Novakovskaia, E., Sloop, C. D., Michelsen, H. A., Bambha, R. P., Weiss, R. F., Keeling, R., and Fischer, M. L.: Estimating methane emissions in California's urban and rural regions using multitower observations, J. Geophys. Res.-Atmos., 121, 1303113049, https://doi.org/10.1002/2016JD025404, 2016.

Jeong, S., Cui, X., Blake, D. R., Miller, B., Montzka, S. A., Andrews, A., Guha, A., Martien, P., Bambha, R. P., LaFranchi, B., Michelsen, H. A., Clements, C. B., Glaize, P., and Fischer, M. L.: Estimating methane emissions from biological and fossil-fuel sources in the San Francisco Bay Area, Geophys. Res. Lett., 44, 486-495, https://doi.org/10.1002/2016GL071794, 2017.

Kaffka, S., Barzee, T., El-Mashad, H., Williams, R., Zicari, S., and Zhang, R.: Evaluation of Dairy Manure Management Practices for Greenhouse Gas Emissions Mitigation in California, available at: http://biomass.ucdavis.edu/wp-content/uploads/2016/06/ ARB-Report-Final-Draft-Transmittal-Feb-26-2016.pdf (last access: 18 April 2017), 2016.

Kennedy, C., Steinberger, J., Gasson, B., Hansen, Y., Hillman, T., Havránek, M., Pataki, D., Phdungsilp, A., Ramaswami, A., and Villalba Mendez, G.: Greenhouse gas emissions from global cities, Environ. Sci. Technol., 43, 7297-7302, https://doi.org/10.1021/es900213p, 2009.

Lyon, D. R., Zavala-Araiza, D., Alvarez, R. A., Harriss, R., Palacios, V., Lan, X., Talbot, R., Lavoie, T., Shepson, P., Yacovitch, T. I., Herndon, S. C., Marchese, A. J., Zimmerle, D., Robinson, A. L., and Hamburg, S. P.: Constructing a Spatially Resolved Methane Emission Inventory for the Barnett Shale Region, Environ. Sci. Technol., 49, 8147-8157, https://doi.org/10.1021/es506359c, 2015. 
Maasakkers, J. D., Jacob, D. J., Sulprizio, M. P., Turner, A. J., Weitz, M., Wirth, T., Hight, C., DeFigueiredo, M., Desai, M., Schmeltz, R., Hockstad, L., Bloom, A. A., Bowman, K. W., Jeong, S., and Fischer, M. L.: Gridded National Inventory of U.S. Methane Emissions, Environ. Sci. Technol., 50, 13123-13133, https://doi.org/10.1021/acs.est.6b02878, 2016.

McKain, K., Down, A., Raciti, S. M., Budney, J., Hutyra, L. R., Floerchinger, C., Herndon, S. C., Nehrkorn, T., Zahniser, M. S., Jackson, R. B., Phillips, N., and Wofsy, S. C.: Methane emissions from natural gas infrastructure and use in the urban region of Boston, Massachusetts, P. Natl. Acad. Sci., 112, 1941-1946, https://doi.org/10.1073/pnas.1416261112, 2015.

Myhre, G., Shindell, D., Bréon, F.-M., Collins, W., Fuglestvedt, J., Huang, J., Koch, D., Lamarque, J.-F., Lee, D., Mendoza, B., Nakajima, T., Robock, A., Stephens, G., Takemura, T., and Zhan, H.: Anthropogenic and Natural Radiative Forcing: In Climate Change 2013: The Physical Science Basis. Contribution of Working Group I to the Fifth Assessment Report of the Intergovernmental Panel on Climate Change, in: Cambridge University Press, Cambridge, United Kingdom and New York, NY, USA, 659-740., 2013.

National Pipeline Mapping System (NPMS): Pipeline and Hazardous Materials Safety Administration; U.S. Department of Transportation: National Pipeline Mapping System, available at: https://www.npms.phmsa.dot.gov/ (last access: 31 March 2017), 2013.

Newman, S., Xu, X., Gurney, K. R., Hsu, Y. K., Li, K. F., Jiang, X., Keeling, R., Feng, S., O'Keefe, D., Patarasuk, R., Wong, K. W., Rao, P., Fischer, M. L., and Yung, Y. L.: Toward consistency between trends in bottom-up $\mathrm{CO}_{2}$ emissions and top-down atmospheric measurements in the Los Angeles megacity, Atmos. Chem. Phys., 16, 3843-3863, https://doi.org/10.5194/acp16-3843-2016, 2016.

Oda, T. and Maksyutov, S.: A very high-resolution $(1 \mathrm{~km} \times 1 \mathrm{~km})$ global fossil fuel $\mathrm{CO}_{2}$ emission inventory derived using a point source database and satellite observations of nighttime lights, Atmos. Chem. Phys., 11, 543-556, https://doi.org/10.5194/acp-11543-2011, 2011.

Olivier, J. and Peters, J.: $\mathrm{CO}_{2}$ from non-energy use of fuels: A global, regional and national perspective based on the IPCC Tier 1 approach, Resour. Conserv. Recycl., 45, 210-225, 2005.

Patarasuk, R., Gurney, K. R., O’Keeffe, D., Song, Y., Huang, J., Rao, P., Buchert, M., Lin, J. C., Mendoza, D., and Ehleringer, J. R.: Urban high-resolution fossil fuel $\mathrm{CO}_{2}$ emissions quantification and exploration of emission drivers for potential policy applications, Urban Ecosyst., 19, 1013-1039, https://doi.org/10.1007/s11252-016-0553-1, 2016.

Perata: Senate Bill No. 1368, Chapter 598, available at: http://www.energy.ca.gov/emission_standards/documents/ sb_1368_bill_20060929_chaptered.pdf (last access: 31 March 2017), 2006.

Rao, P., Gurney, K. R., Patarasuk, R., Yang, S., Miller, C. E., Duren, R. M., and Eldering, A.: Spatio-temporal variations in on-road $\mathrm{CO}_{2}$ emissions in the Los Angeles Megacity, AIMS Geosci., 3, 239-267, https://doi.org/10.3934/geosci.2017.2.239, 2017.

State Water Resources Control Board (SWRCB), Regulated Facility Report 2016, available at: https://ciwqs.waterboards. ca.gov/ciwqs/readOnly/CiwqsReportServlet?inCommand=
reset\&reportName=RegulatedFacility (last access: 22 June 2017), 2016

Townsend-Small, A., Tyler, S. C., Pataki, D. E., Xu, X., and Christensen, L. E.: Isotopic measurements of atmospheric methane in Los Angeles, California, USA: Influence of "fugitive" fossil fuel emissions, J. Geophys. Res.-Atmos., 117, 1-11, https://doi.org/10.1029/2011JD016826, 2012.

U.S. Energy Information Administration: Refinery Capacity Report, U.S. Energy Information Administration, 2015.

U.S. Environmental Protection Agency: EPA Facility Registry Service (FRS): Wastewater Treatment Plants, Data.Gov, available at: https://catalog.data.gov/dataset/ epa-facility-registry-service-frs-wastewater-treatment-plants, last access: 31 December, 2016.

Verhulst, K. R., Karion, A., Kim, J., Salameh, P. K., Keeling, R. F., Newman, S., Miller, J., Sloop, C., Pongetti, T., Rao, P., Wong, C., Hopkins, F. M., Yadav, V., Weiss, R. F., Duren, R. M., and Miller, C. E.: Carbon dioxide and methane measurements from the Los Angeles Megacity Carbon Project - Part 1: calibration, urban enhancements, and uncertainty estimates, Atmos. Chem. Phys., 17 8313-8341, https://doi.org/10.5194/acp-17-8313-2017, 2017.

Viatte, C., Lauvaux, T., Hedelius, J. K., Parker, H., Chen, J., Jones, T., Franklin, J. E., Deng, A. J., Gaudet, B., Verhulst, K., Duren, R., Wunch, D., Roehl, C., Dubey, M. K., Wofsy, S., and Wennberg, P. O.: Methane emissions from dairies in the Los Angeles Basin, Atmos. Chem. Phys., 17, 7509-7528, https://doi.org/10.5194/acp-17-7509-2017, 2017.

Wennberg, P. O., Mui, W., Wunch, D., Kort, E. A., Blake, D. R., Atlas, E. L., Santoni, G. W., Wofsy, S. C., Diskin, G. S., Jeong, S., and Fischer, M. L.: On the sources of methane to the Los Angeles atmosphere, Environ. Sci. Technol., 46, 9282-9289, https://doi.org/10.1021/es301138y, 2012.

Wong, C. K., Pongetti, T. J., Oda, T., Rao, P., Gurney, K. R., Newman, S., Duren, R. M., Miller, C. E., Yung, Y. L., and Sander, S P.: Monthly trends of methane emissions in Los Angeles from 2011 to 2015 inferred by CLARS-FTS observations, Atmos. Chem. Phys., 16, 13121-13130, https://doi.org/10.5194/acp-1613121-2016, 2016.

Wong, K. W., Fu, D., Pongetti, T. J., Newman, S., Kort, E. A., Duren, R., Hsu, Y.-K., Miller, C. E., Yung, Y. L., and Sander, S. P.: Mapping $\mathrm{CH}_{4}: \mathrm{CO}_{2}$ ratios in Los Angeles with CLARSFTS from Mount Wilson, California, Atmos. Chem. Phys., 15, 241-252, https://doi.org/10.5194/acp-15-241-2015, 2015.

Wunch, D., Wennberg, P. O., Toon, G. C., Keppel-Aleks, G., and Yavin, Y. G.: Emissions of greenhouse gases from a North American megacity, Geophys. Res. Lett., 36, 1-5, https://doi.org/10.1029/2009GL039825, 2009.

Yuan, J.: Automatic Building Extraction in Aerial Scenes Using Convolutional Networks, available at: https://arxiv.org/abs/1602. 06564 (last access: 31 March 2017), 2016.

Zavala-Araiza, D., Lyon, D. R., Alvarez, R. A., Davis, K. J., Harriss, R., Herndon, S. C., Karion, A., Kort, E. A., Lamb, B. K., Lan, X., Marchese, A. J., Pacala, S. W., Robinson, A. L., Shepson, P. B., Sweeney, C., Talbot, R., Townsend-Small, A., Yacovitch, T. I., Zimmerle, D. J., and Hamburg, S. P.: Reconciling divergent estimates of oil and gas methane emissions, P. Natl. Acad. Sci., 112, 15597-15602, https://doi.org/10.1073/pnas.1522126112, 2015. 